\title{
Reconstructing Van Gogh's palette to determine the optical characteristics of his paints
}

\author{
Muriel Geldof ${ }^{*}\left(\mathbb{D}\right.$, Art Ness Proaño Gaibor ${ }^{1}$, Frank Ligterink ${ }^{1}$, Ella Hendriks ${ }^{2}$ and Eric Kirchner ${ }^{3}$
}

\begin{abstract}
The colors of Field with Irises near Arles, painted by Van Gogh in Arles in 1888, have changed considerably. To get an idea of how this painting, as well as other works by Van Gogh, looked shortly after their production, the Revigo (Reassessing Vincent van Gogh's colors) research project was initiated. The aim of this project was to digitally visualize the original colors of paintings and drawings by Vincent van Gogh, using scientific methods backed by expert judgement where required. We adopted an experimental art technological approach and physically reconstructed Van Gogh's full palette of oil paints, closely matching those he used to paint Field with Irises near Arles. Sixteen different paints were reconstructed, among which the most light-sensitive pigments and linseed oil, which is prone to yellowing, were produced according to 19th century practice. The resulting pigments and oils were chemically analyzed and compared to those used by Van Gogh. The ones that resembled his paints the most were used in the paint reconstructions. Other pigments were either obtained from the Cultural Heritage Agency's collection of historical pigments, or purchased from Kremer Pigmente. The reconstructed paints were subsequently used to calculate the absorption $\mathrm{K}$ and scattering S parameters of the individual paints. Using Kubelka-Munk theory, these optical parameters could in turn be used to determine the color of paint mixtures. We applied this method successfully to digitally visualize the original colors of Field with Irises near Arles. Moreover, the set of optical parameters presented here can similarly be applied to calculate digital visualizations of other paintings by Van Gogh and his contemporaries.
\end{abstract}

Keywords: Vincent Van Gogh, Pigments, Oil paints, Color, Kubelka-Munk theory

\section{Introduction}

Many paintings by Van Gogh and his contemporaries have severely changed color since they were made [1-7]. The painting Field with Irises near Arles (Fig. 1), painted by Van Gogh in Arles in May 1888, is no exception. Several factors may account for color change, such as: natural aging and light-induced color change of paints, past restoration treatments and deposited surface dirt. In the period 2013 to 2015, Field with Irises near Arles was subject to full technical examination and conservation treatment in the Van Gogh Museum. Surface dirt and a varnish layer that had been added to the painting during restoration treatment in $1927,{ }^{1}$ were removed. Since the aged varnish layer had strongly yellowed and gave the painting an inappropriate gloss-the painting was intended to be left unvarnished-, this cleaning treatment had a profound effect on the overall color scheme and appearance of the painting, lifting the brightness of the colors.

Besides external factors, also Van Gogh's choice of materials has led to color changes in Field with Irises near Arles, especially his use of the very light-sensitive red paints cochineal and eosin, and chrome yellow. Several historical sources, including early reproductions

\footnotetext{
*Correspondence: m.geldof@cultureelerfgoed.nl

${ }^{1}$ Cultural Heritage Agency of the Netherlands (RCE), Hobbemastraat 22,

1071 ZC Amsterdam, The Netherlands

Full list of author information is available at the end of the article
}

\footnotetext{
${ }^{1}$ A bill dated August 1927 records the application of this varnish by the Dutch conservator, Jan Cornelis Traas, Inv. Nr. B 4214 v/1962, archives Van Gogh Museum, Amsterdam.
} 


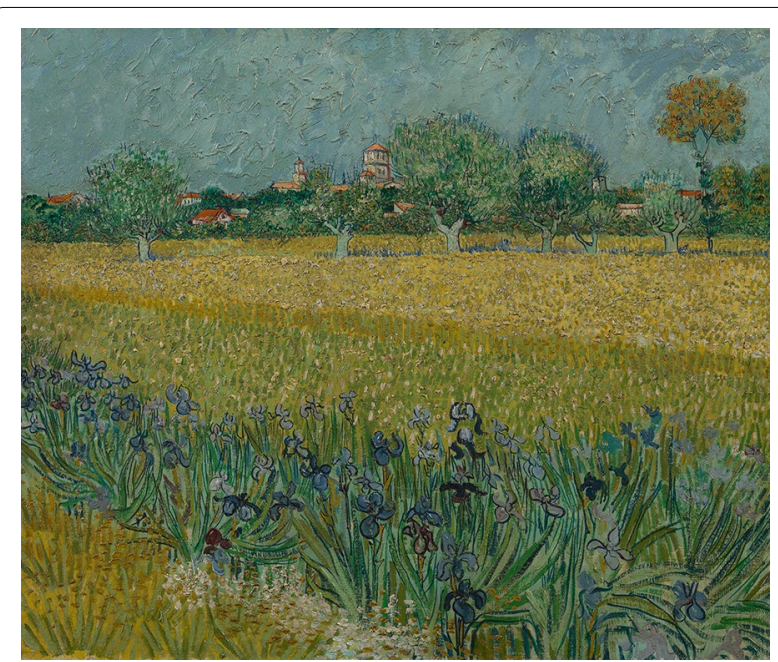

Fig. 1 Vincent van Gogh, Field with Irises near Arles (F409), 1888, Van Gogh Museum, Amsterdam (Vincent van Gogh Foundation)

and descriptions of the painting, already indicate the alteration of these colors. In a letter Vincent wrote to his brother Theo on Saturday 12 May 1888, he describes this painting as depicting 'A meadow full of very yellow buttercups, a ditch with iris plants with green leaves, with purple flowers, ... (letter 609). Nowadays the buttercups look somewhat dull ochreish yellow and most of the irises appear more bluish than purple due to fading of the red pigments. Also microscopic examination of the painting provided clear signs of color changes, particularly around the edges of the painting where the paint has been shielded from light by paper tape applied during the 1927 restoration. These cumulative observations made it intriguing to imagine how brightly colored his paintings may have looked like originally. Therefore in 2013 the NWO-funded Science4Arts-Revigo research project was initiated with the objective to digitally reconstruct the original colors of paintings and drawings by Vincent van Gogh, using scientific methods as far as possible.

Pioneering work on digital color reconstruction ('rejuvenation') of historic paintings has been conducted by Berns following a hybrid strategy of spectral reflectance measurements and photographic image color segmentation [8]. Georges Seurat used a zinc yellow paint that darkened over time, affecting pointillist dabs of yellow, orange and green, made from zinc yellow; zinc yellow, vermilion, and white; and zinc yellow, emerald green, and white, respectively. This darkening occurred for his iconic painting, A Sunday on La Grande Jatte, dated 1884. Kubelka-Munk theory was used to create an optical database of these paints and concentrations were determined for each measurement using nonlinear optimization minimizing spectral reflectance root-mean-square difference.
Using a laboratory dispersion of zinc yellow and linseed oil, the darkened zinc yellow was replaced with the laboratory dispersion for measurements representing each color. Color changes between the measurement before and after the paint replacement was used to create custom curves that were used for segmented areas of La Grande Jatte. Berns used the same technique in producing color reconstructions of two of the three versions of Van Gogh's Bedroom where eosin and cochineal lake pigments faded [9]. Because the concentration of the faded paints could not be determined, a team of curators and conservators made informed decisions on concentration.

Another important advancement in support of digital color reconstruction has been the development by Delaney [10] of a dedicated hyperspectral imaging camera system that can operate at safely low illumination levels. The availability of spectral image data for the complete painting Field with Irises near Arles for our research importantly extended the possibilities for digital color reconstruction.

In addition to these two developments, comprehensive campaigns of technical and analytical investigation of Van Gogh's paintings conducted over the last decades had resulted in an extensive body of knowledge concerning their material composition and making process [11, 12]. While this undoubtedly provides an invaluable resource of knowledge to support color reconstruction, in practice it proved difficult to systematically combine spectral image data with knowledge about material composition to make informed inferences about color. This difficulty essentially hinges on the large amount of colors present in the painting as a result of subtle variations in the mixing of paints. For practical reasons it is simply not feasible to model the behavior of each of these colors individually. In order to bridge these two aspects and avoid the necessity to separately model thousands of colors, we adopted an experimental art technological approach by physically reconstructing the full palette of oil paints closely matching those used by Vincent van Gogh to paint Field with Irises near Arles. The palette on one hand represents a model system that effectively encodes our knowledge about the materials used by Van Gogh. On the other hand this complete set of reconstructed paints could be used to measure the optical properties of the individual paints and subsequently calculate the color of any particular paint mixture. Within the framework of KubelkaMunk theory, these optical properties (i.e. absorption and scattering) are all that is required to predict the color of specific paint mixtures. In other words, by physically reconstructing the paints that Van Gogh used, we are able to virtually mix them and reconstruct the original colors of Field with Irises near Arles. 
In three earlier publications [13-15] we reported on the processing of the hyper spectral image data for Field with Irises near Arles: varnish removal, calculation of pigment concentration maps and color reconstruction. In this concluding article we describe how we manufactured the oil paints and how their optical properties were measured and calculated.

\section{Paint reconstructions}

To make a convincing reconstruction of Van Gogh's palette, we need pigments and binders that resemble those used by Van Gogh. Fortunately, Van Gogh's paints have thoroughly been investigated $[1,2,12,16,17]$, providing us with much information on the properties our paint reconstructions should mimic. Also, in the past several reconstructions were made of Van Gogh's paints. Carlyle set the standard in the HART (Historically Accurate Reconstructions Techniques) Project conducted from 2002 to 2006 as part of the De Mayerne Programme, in which both oil paint and ground reconstructions were made with as much accuracy as feasible in order to explore historical recipes and workshop practices [18]. Part of the project involved the reconstruction of Van Gogh's grounds and white paints in order to investigate their working properties [19]. In the same period several of Van Gogh's red lake paints were reconstructed as part of a collaborative project on the 'Fading of red lake paints after Vincent van Gogh' led by Klaas Jan van den Berg (Cultural Heritage Agency of the Netherlands). The paint reconstructions, based on analysis of Van Goghs paints and using 19th-century English and French recipes, were prepared in two workshops: one on pigment preparation led by Jo Kirby and David Saunders (formerly National Gallery, London, United Kingdom) [20] and another on grinding pigments with oil to make paints under the guidance of Leslie Carlyle. Also, the paint outs were artificially aged to better understand the color changes that have taken place in Van Gogh's paintings [3]. This provided a wealth of information about the handling properties, color and aging behavior of his paints. However, it also revealed the limitations of the experimental approach: lack of information on the recipes used by 19th century paint manufacturers in general and those of Van Gogh in particular, as well as the 21stcentury laboratory scale conditions used, restricted the historical accuracy of the paint preparations that could be accomplished $[18,19]$. While additional information on 19th century recipes and the composition of Van Gogh paints has become available since then, these constraints will never be fully overcome. Moreover, when reconstructing Van Goghs full palette, further compromises had to be made due to practical limitations and time constraints.
Table 1 Provenance of the binding media

\begin{tabular}{ll}
\hline Binding medium & Provenance \\
\hline Linseed oil & Home-made windmill pressed, water washed oil \\
Poppyseed oil & Talens and Kremer Pigmente \\
Paraffin wax & Van Beek Art supplies \\
\hline
\end{tabular}

\section{Oil binder}

Yellowing of drying oils in paintings is a well-known phenomenon and has been a concern of artists for centuries [21-24]. The extent of this colour change depends on the type of oil used, therefore the selection of the right binding media for Van Gogh's paint reconstructions is crucial.

Chemical analysis of the binding media of Van Gogh's paints identified poppyseed oil in zinc white and lead white paints and linseed oil in cochineal and geranium lake paints, with some paraffin wax added to the latter as well $[2,17]$. Since linseed oil is known to be more prone to yellowing during ageing than poppyseed oil, we decided to produce linseed oil according to 19th century oil pressing methods, as described in the section below, while poppyseed oil was commercially purchased. Paraffin wax is not expected to contribute much to color change either and so was also bought as such (Table 1).

\section{Flaxseeds}

The starting point for the production of linseed oil in our project was the selection of seeds. Most flax plants in the world belong to the species Linum usitatissimum $\mathrm{L}$. The flax plant is used for two main raw materials; its fibres and its oil. There are hundreds of cultivars of flax plants, but they can be divided into two main types: one grows specifically to produce oil (linseeds), the other to produce linen fibres (flaxseeds).

In the 20th century, cultivar manipulation practices, like clarifying the husks of the seeds or enriching oil yield, have extensively been applied and as a result the oil available today differs from the 19th century linseed oil. Because of this, we chose to use flaxseeds for our oil reconstruction instead of modern linseeds, believing that the oil in these seeds was not tampered with as much as the linseeds that are now on the global market.

Carlyle also produced oil from flaxseeds during her Fellowship within the MolArt project (Molecular Aspects of Ageing in Painted Works of Art) in 1999, and again in 2005. This oil was subsequently used in the De Mayerne projects for the reconstruction of Van Gogh's ground and paints. The oil was expressed from flaxseeds Electra cultivar $^{2}$ with a hydraulic press developed within the pro-

\footnotetext{
${ }^{2}$ The seeds were supplied by Flevo vlas loonwerk B.V. See Carlyle L, Witlox M, Pilz K. HART project, Lead white report/Appendix II. Unpublished report, May 2005; pp. 70-71.
} 
ject. The Electra cultivar flaxseed was certified in the 1980s by the European Union [25] and was at that time one of the oldest certified cultivars. However, in the last decades this cultivar became contaminated with genetically modified genes. Hence, in 2013-when the Revigo project started-European legislation revoked its permit and the cultivar was no longer available in the Netherlands. Therefore, we looked for a substitute cultivar and eventually chose flaxseed cultivar Sofie supplied by Van de Bilt zaden B.V. in Sluiskil, The Netherlands. The seeds we purchased were harvested in the Summer of 2013. The Sofie cultivar has not been contaminated with transgenes and the seeds originate possibly from the Baltic region; the use of linseed from this region was highly recommended in 19th century source literature on artist materials $[26,27]$.

\section{9th century pressing of linseed}

In Van Gogh's time, there were two methods to obtain oil from flaxseeds; mechanical expression (or press extraction) and chemical extraction. In chemical extraction, volatile solvents are used and-in contrast to mechanical expression-no pressure is applied ${ }^{3}[28,29]$. Since medieval times however the most common method has been mechanical expression.

The two main mechanical expression methods were hydraulic pressing and windmill powered expression. Both were used to produce linseed oil for artists' paints $[28,30,31]$. In the Netherlands and in Belgium extraction of linseed oil was chiefly done with the use of wind power until the 1900s [32,33]. Windmills were equipped with a 'Kollergang' (two edge runner stones rolling on the pan) that crushed the seeds, which were then wrapped in filter cloths and expressed with a wedge press. The hydraulic press was invented by Joseph Bramah in 1795; the expression outlet of his press was based on the traditional oil mill method with filter cloths. At the end of the 19th century German companies produced hydraulic cage presses, with rams pressing the seeds inside of vertical slotted barrels that did not require filter cloths [29]. The hydraulic press developed during Carlyle's MolArtfellowship, is based on these clothless models but works horizontally instead of vertically.

Both hydraulic and windmill wedge pressing were performed in our project to compare methods and make a well-considered choice for the historical reconstructions. Hydraulic pressing was done with the MolArt hydraulic press that is now placed at the Faculty of Science and Technology, Universidade Nova de Lisboa. Before hydraulic pressing the Sofie cultivar flaxseeds

\footnotetext{
${ }^{3}$ Note that solvent extraction is often coupled with a mechanical screwpress.
}

were ground with a Molinex coffee grinder. The maximum pressure applied during expression was 300 bar; a pressure comparable to the pressure produced in a windmill. Due to a low extraction rate of $13.5 \mathrm{ml}$ oil per hour, only 5.2 kilograms of flaxseed could be processed during a 1 week visit to Lisbon, which resulted in a total of $859.9 \mathrm{ml}$ of linseed oil.

The windmill extraction was performed in oil windmill 't Pink (anno 1620) in the town of Koog aan de Zaan, which has existed in its present form since 1751 . Before pressing the flaxseed cultivar Sofie, the windmill was thoroughly cleaned to avoid contamination from earlier pressed linseeds. The expression started with crushing the seeds under the 'Kollergang.' The crushed seeds (the so-called 'meal') were then collected and heated on an iron stove plate (peat bog fuelled), with the addition of a little water, under constant stirring until the meal was lukewarm. Then the meal was gathered in filter cloths and wrapped in leather sheaths, lined with braided horse hair and placed in the wedge press. The pressing wedge was hammered by the ram block, to build up a pressure between 200 and 300 bar. The oil was then recovered in a stainless-steel container and transferred into one litre transparent glass jars. An approximate volume of $28 \mathrm{l}$ of oil was obtained.

\section{Washing the oil}

The windmill expressed linseed oil contained much more mucilage than the hydraulic pressed oil. Therefore it was necessary to wash the windmill oil, as was common practice from the 17th until the 19th century [30]. We did not use a historical recipe, but instead utilized the working principles as described by Witlox ${ }^{4}$ for different waterwashing recipes. After washing, the oil was stored in closed translucent plastic bottles under moderate light conditions.

\footnotetext{
$\overline{{ }^{4}}$ M. Witlox, Molart Fellowship Report, Unpublished report, April 2000, p. 43.

We used the following procedure: 151 of windmill pressed linseed oil were divided in two wide mouth plastic bottles with spigot each of $15 \mathrm{l}$. The bottles were filled up each day with 7.51 of demineralized water and were shaken for $10 \mathrm{~min}$. The bottles were left to rest for $24 \mathrm{~h}$ and then the spigots were opened to let the water including the mucilage escape, after which new demineralized water could be added. This lasted for 8 weeks.

Mould was produced in the oil once when no daily access was possible to renew the water deposit, due to national holidays. Pressure in the bottles had risen and when the bottles opened a putrid smell had been produced. The oil was filtered with a linen cloth to remove the mould and the extra mucilage that had precipitated. Then the washing continued, and after 2 days the sulphurous smell disappeared.

A study by Kneepkens et al. has shown that evaporating the water in the oil by heating leads to a glossy oil film when dry [34]. We did not choose to boil the possible remaining water from the oil because there is hardly any literature available about this procedure. This is possibly the reason that our paint reconstructions made with water-washed linseed oil resulted in a quite mat oil film when dry.
} 


\section{Characterization of the linseed oil}

Linseed oil consists of triglycerides: glycerol triesters of primarily unsaturated fatty acids. It is distinctive for its relative large amount of triply unsaturated $\alpha$-linolenic acid (ca. 50\%). During drying the unsaturated bonds cross-link via an oxidation process and form a threedimensional network. Also, other chemical reactions take place such as hydrolysis of the ester bonds resulting in free fatty acids.

To characterize the linseed oils produced, both the hydraulic and wind-mill expressed linseed oils were subjected to a series of chemical analyses: the amount of free fatty acids (acid value) and the degree of unsaturation in the fatty acids (iodine value) were determined to record their starting conditions and quality, and to compare them with each other. In addition, full chemical analysis of the triglycerides of the raw wind-mill oil was performed.

Determination of the free fatty acid content in oil The acid values - the amount of free fatty acids in the oil-of the hydraulic and windmill pressed linseed oils were determined according to the standard procedure (Table 2). ${ }^{5}$

The raw windmill pressed oil has an acid value that varies between 2.8 and 3.0 depending on the storage conditions of the oil, which is much larger than the acid value of 0.61 to 0.89 of the hydraulic pressed oil. This is presumably due to the way the seeds were crushed in the mill: some water was added and the crushed seeds were slightly heated before pressing, which promotes the hydrolysis of the ester bonds. For the same reason a slight increase in acidity is also observed after water washing the oil. Using different storage conditions does not influence the acidity of the oil much.

Nowadays linseed oils for painting meet high standards: Alberdingk-Boley-today Europe's biggest producer of linseed oil-states for example that the acid value of their refined linseed oil does not exceed 1 [35]. However, in the past these standards were probably lower. In a standard specification order of the Minister for Industry and Commerce of Ireland issued in 1949, it is declared that the maximum acid value allowed for raw linseed oil used for paints is 6 , and for non-acid refined linseed oil the maximum value is 4 [36].

Determination of degree of unsaturation in fatty acids To determine the iodine values of the oils-a measure for the

${ }^{5}$ NEN-EN-ISO 660 -Animal and vegetable fats and oils-determination of acid value and acidity (ISO 660:2009, IDT). degree of unsaturation in the oils - the Hanus method was used. ${ }^{6}$

The hydraulic and the windmill pressed oils have similar average iodine values (Table 3). The standard deviation in the measurements is relative high due to the different storage conditions used, which, as expected, influence the degree of unsaturation in the oils. For instance, exposure of the oil to oxygen will lead to oxidation of the double bonds and therefore to a decrease in the iodine value. A small increase in the iodine value was observed after washing the oil, probably due to the fact that the mucilage has been removed which results in a purer oil.

Identification of triglycerides The raw windmill pressed oil was studied by means of a novel LC-ESI-MS method developed by Van Dam et al. [37]. The fatty acid level of the raw linseed oil contains c. $10-11 \%$ saturated fatty acids (palmitic and stearic acid), 19-22\% oleic acid, 14-17\% linoleic acid and $52-55 \% \alpha$-linolenic acid. It was found that the oil consists mainly of tri acyl glycerides (TAGs) with alkyl chains lengths of 16 and 18 carbon atoms and 2-9 double bonds. The component ratios are in accordance with literature values for fresh linseed oils [38, 39].

\section{Yellow coloured components}

The windmill and hydraulic pressed oils show a remarkable colour difference: the windmill oil is a darker yellow than the hydraulic pressed oil, also after water-washing [34]. Since the pressure in both expressing methods was the same, it seems likely that the colour difference is caused by the crushing of the seeds. P.F. Tingry noted already in 1804 that "the kernel of flaxseed is enclosed in a small hard covering. The kernel only will give a colourless oil like that of pinks" (= poppy seed oil) [40]. Therefore, we decided to scrutinize the seeds themselves.

We started by separating the colourless kernel of the seed from the husk. To extract the unknown colorants from the husks, they were put in $100 \mu \mathrm{l}$ dimethyl sulfoxide and heated to $70{ }^{\circ} \mathrm{C}-$ a standard extraction procedure for unknown colorants. After 10 min a light yellowish solution was obtained that was analysed with UHPLCPDA to detect the colorants. ${ }^{7}$ A 4 min broad peak with

\footnotetext{
${ }^{6}$ We used the following procedure: the oils were dissolved in chloroform:methanol (1:1) and $0.1 \mathrm{M}$ iodine monobromide (Hanuš solution) was added. The solution was left to react for two hours and was afterwards titrated with $0.1 \mathrm{M}$ sodium thiosulfate.

7 The following procedure was used: $5 \mu$ of the extract was analysed with a chromatography apparatus (Waters ${ }^{\circledR}$ ACQUITY UPLC H-Class System) (UHPLC). The column used is a $15 \mathrm{~cm}$ BEH (Ethylene Bridged Hybrid) column with pre-filter. Automatically manage gradient of A: $10 \%$ methanol in water, B: $100 \%$ methanol and C: $1 \%$ formic acid. A photodiode array detector (with wave length $200-800 \mathrm{~nm}$ ) was used to detect the organic colorants.
} 
Table 2 Acid values of the linseed oils

\begin{tabular}{|c|c|c|}
\hline Oil & Acid value (mg KOH/g oil) & Remarks \\
\hline Hydraulic pressed oil_-raw & $0.61-0.89$ & $\begin{array}{l}\text { Results of } 9 \text { measurements, oil kept in different conditions for a few months } \\
\text { (light, dark, closed and open vessel) }\end{array}$ \\
\hline Windmill pressed oil_-raw & $2.8-3.0$ & $\begin{array}{l}\text { Results of } 11 \text { measurements, oil kept in different conditions for a few } \\
\text { months (light, dark, closed and open vessel) }\end{array}$ \\
\hline Windmill pressed oil—washed & 3.7 & Average of duplicate measurement \\
\hline Commercial refined linseed oil for oil paints & Max. 1 & Alberdingk-Boley, Germany \\
\hline Raw linseed oil for paints & Max. 6 & Daniel Morrissey Order, 1949, Ireland \\
\hline Non-acid refined linseed oil for paints & Max. 4 & \\
\hline
\end{tabular}

Table 3 lodine values of the linseed oils

\begin{tabular}{|c|c|c|}
\hline Oil & lodine value ( $\mathrm{g} \mathrm{I}_{2} / 100 \mathrm{~g}$ oil) & Remarks \\
\hline Hydraulic pressed oil_raw & $186.8 \pm 7.47$ & $\begin{array}{l}15 \text { measurements, oil kept in different conditions for a few months (light, } \\
\text { dark, closed and open vessel) }\end{array}$ \\
\hline Windmill pressed oil_raw & $184.6 \pm 4.5$ & $\begin{array}{l}21 \text { measurements, oil kept in different conditions for a few months (light, } \\
\text { dark, closed and open vessel) }\end{array}$ \\
\hline Windmill pressed oil—washed & $189.0 \pm 1.1$ & Duplicate measurement \\
\hline Commercial refined linseed oil for oil paints & Min. 175 & Alberdingk-Boley, Germany \\
\hline
\end{tabular}

retention time of around $17 \mathrm{~min}$ was observed. The absorption spectrum of this peak has a maximum wavelength absorption of $286.7 \mathrm{~nm}$ and is therefore a colourless component (Fig. 2a).

Several studies have been undertaken to investigate the yellowing of linseed oil in paint films, leading to various hypotheses [41-43]. Privett concluded in 1961 that the yellowing of drying oil involves two distinct steps: the formation of a colourless precursor by an oxidative mechanism followed by further reaction of the precursor-probably in some type of condensation reaction-to yield the yellow compounds. The colourless precursor has an absorption maximum of around $270 \mathrm{~nm}$, which is similar to the absorption of the component found in the husks extraction. The same colourless precursor was also detected in both the raw and water-washed windmill pressed linseed oils, as well as in the hydraulic pressed oil.

In an attempt to provoke the formation of yellow compounds as found by Privett we exposed the husks extraction solution to several conditions. When the extraction solution was heated to $100{ }^{\circ} \mathrm{C}$ for $10 \mathrm{~min}$ with the addition of $50 \mu \mathrm{l}$ concentrated $\mathrm{HCl} /$ water/methanol (2:1:1), it turned dark brown. The excess hydrochloric acid was evaporated under a nitrogen flow and the brown solution was analysed. This time several components were detected with UHPLC-PDA that have a clear yellow colour. One component has a maximum absorption of $477.4 \mathrm{~nm}$ and another of $472.6 \mathrm{~nm}$ (Fig. 2b). These yellow components are possibly obtained through chemical reaction of the colourless component eluting at $17 \mathrm{~min}$. It is known that hydrochloric acid $(\mathrm{HCl})$ can act as a catalyst in condensation reactions, which would be in agreement with Privett's suggestion that these play a role in the formation of the yellow compounds. After a few weeks the brown solution was considerably lighter in colour, which indicates that the yellow colorants are unstable.

\section{Choice of linseed oil for reconstructions}

Both windmill and hydraulic pressed oils have been used in the 19th century. However, we preferred to use the water-washed windmill pressed oil above the hydraulic pressed oil for several reasons. Firstly, by using the windmill extraction method relative large amounts of linseed oil could be pressed at once; if we had used the hydraulic press at our disposal instead, the process would have been far more time consuming. Furthermore, the waterwashed windmill oil has a somewhat lower quality-a higher acid value and a more yellow colour-than the hydraulic pressed oil, which is possibly what one might expect for a linseed oil produced in the 19th century.

\section{Pigments}

Van Gogh painted Field with Irises near Arles with a pigment palette that is characteristic for his Arles period. It consisted of at least 14 different pigments and two extenders. He used the whites lead white and zinc white, the red paints vermilion, red lead, eosin and cochineal, the green paints emerald green and viridian and the blues Prussian blue, synthetic ultramarine blue and cobalt 
blue $[14,17]$. Recent SEM-WDS analysis confirmed our earlier observation that Van Gogh also used two different types of chrome yellow in the painting [14, 44]. The extenders barium sulphate and calcium carbonate white were identified, added to emerald green and chrome yellow paint respectively. The pigments and extenders identified in Field with Irises near Arles were all acquired for this research and made into oil paints. The pigments used for reconstruction fall into three categories: the first category consists of the pigments which we produced based on 19th century recipes, a second group of pigments was taken from the historical pigment collection of the Cultural Heritage Agency of the Netherlands (RCE) and the last group of pigments was obtained from Kremer Pigmente.

\section{Pigments made according to 19th century recipes}

Van Gogh used the two organic red paints, eosin on an aluminum-based substrate and an aluminum- and calcium-based cochineal, extensively in Field with Irises near Arles. Both paints are known to be very light sensitive $[1-5,7,45,46]$. The irises in Field with Irises near Arles were among the details Van Gogh painted with mixtures of lead white, cochineal and synthetic ultramarine, onto which he applied pure touches of eosin and cochineal paint. Also the-now-white flowers in the yellow field in the background contain cochineal, as recently confirmed by Ultra High Performance Liquid Chromatography analysis (UHPLC). Because of the large contribution of the faded organic red pigments to the overall color change of the painting, the close reproduction of these pigments is very important.

Already in 2003 several of Van Gogh's red lake pigments, including eosin and cochineal lakes, were reconstructed $[3,20]$. The 2003 reconstruction pigments were thoroughly analyzed ${ }^{8}$ to determine the extent to which they resemble the pigments based on cochineal and eosin found in Field with Irises near Arles, since the same recipe could then be used in our study. The results of the analysis were compared to earlier findings from red lake-containing paint samples taken from Van Gogh's Arles-period paintings. It appeared that the 2003 eosin and cochineal differ in several respects from the pigments actually used by Van Gogh. For example, the cochineal pigment as

\footnotetext{
$\overline{8}$ High performance liquid chromatography (HPLC), performed by Maarten van Bommel (formerly Conservation Scientist at the RCE, currently Professor of Conservation Science at the University of Amsterdam), was used to identify the dyestuff components. Scanning Electron Microscopy with Energy Dispersive X-ray analysis (SEM-EDX) and Fourier Transform Infra Red spectrometry (FTIR), performed by Suzan de Groot (Conservation Scientist at the RCE), were used to determine the composition of the substrate. Furthermore, optical microscopy and micro-VIS-spectrometry were used to examine the morphology, transparency, color and UV-fluorescence of the pigments.
}

reconstructed in 2003 contained too much of the alumina substrate, lacked the calcium found in Van Gogh's paints and was purple rather than the intended crimson. ${ }^{9}$ Therefore the eosin and cochineal pigments were reconstructed anew in 2014 by adjusting the recipes in a workshop led by Maarten van Bommel (Programme Conservation and Restoration of Cultural Heritage, University of Amsterdam, The Netherlands) and Jo Kirby (independent scholar, formerly National Gallery, London, United Kingdom). For each pigment the possible reasons for the differences were determined and a new set of recipes established based on further research and the experience of the workshop leaders [48]. The pigment reconstructions created during the 2014 workshop were investigated using the same techniques as for the 2003 reconstructions. The pigments that were the most similar to the ones used by Van Gogh were chosen to be used in our palette reconstruction. It appeared that the similarity had indeed been improved. Comparison of the various reconstructed cochineal pigments revealed that that the commercial product Carmine Naccarat from Kremer Pigmente shows the best resemblance to the aluminum- and calcium-based cochineal pigment used by Van Gogh. For eosin one of the home-made products was the most similar (Table 4).

Not only the organic red paints have been susceptible to light induced color change. Also chrome yellow is known to be prone to darkening or browning due to photochemical reduction of the pigment. This concerns especially the sulphate-rich, orthorhombic variety of the pigment; the monoclinic lead chromate variety appears to be much more lightfast [49-51]. However, in Field with Irises near Arles it is striking that especially the presumed pure lead chromate yellow buttercups in the foreground turned brown. Microscopic examination showed spotty remnants of material deposited on top of the bright yellow paint, concentrated in the hollows of impasto. This indicates that in this case the color change is not so much caused by light induced surface darkening of the pigment, but rather that external factors play a role, as brown remnants of restoration materials seem to have become embedded in the softened surface of the paint. ${ }^{10}$ Van Gogh probably used at least two different

\footnotetext{
${ }^{9}$ Recently, work by Vitorino et al. indicated that it is indeed the addition of calcium ions during the pigment manufacturing process that leads to a beautiful red-instead of pink- or purplish-red-pigment [47].

${ }^{10}$ During restoration treatment it was noticed by Ella Hendriks (formerly Senior Conservator at the Van Gogh Museum, currently Professor of Conservation and Restoration of Cultural Heritage at the University of Amsterdam) that the pure lead chromate variety of chrome yellow paint is in deteriorated and vulnerable condition, as often appears to be the case in other works by the painter too. The translucent brown residues are most likely left from a facing or other materials applied to the painting when it was wax-resin lined and varnished in 1927.
} 


\section{a Chromatograph and spectra of husks extraction}

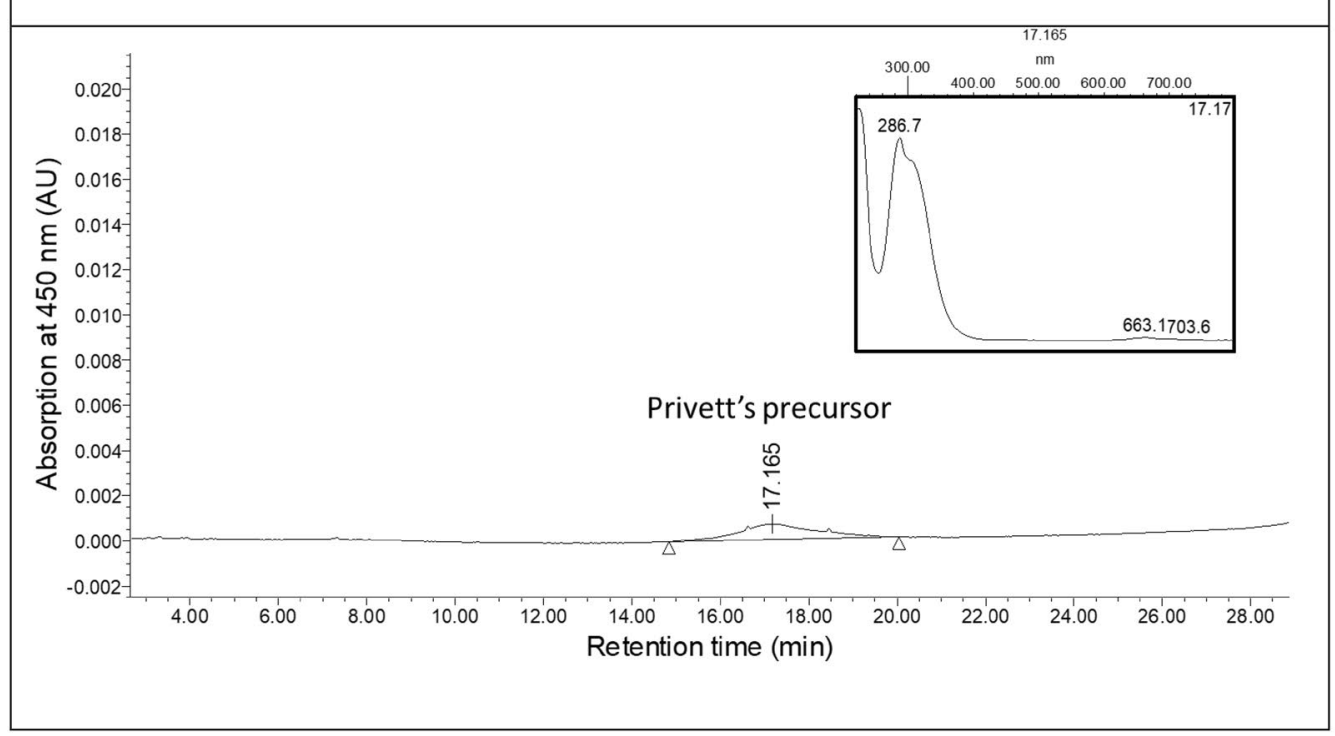

\section{b Chromatograph and spectra of husks extraction}

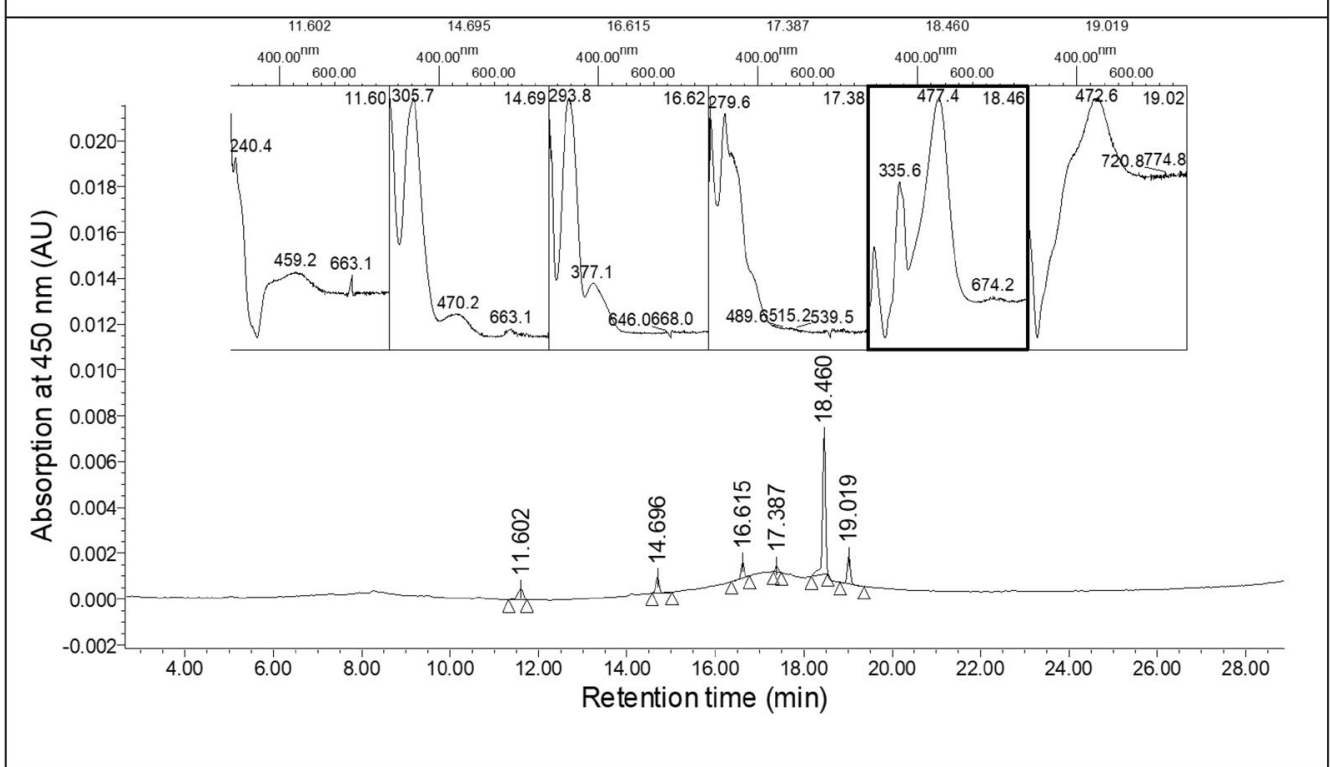

Fig. 2 UHPLC-PDA results of husk extraction (a) Chromatograph and spectra of husks extracted with dimethyl sulfoxide, heated to $70^{\circ} \mathrm{C}(\mathbf{b})$ after subsequent addition of $50 \mu \mathrm{l}$ concentrated $\mathrm{HCl} /$ water/methanol $(2: 1: 1)$ and heated to $100^{\circ} \mathrm{C}$ 
Table 4 Overview of the paint reconstructions made

\begin{tabular}{|c|c|c|}
\hline Pigment & Provenance & Binding medium \\
\hline Zinc white & Kremer Pigmente'zinc white' & Poppyseed oil \\
\hline Lead white & RCE reference collection, Schoonhoven de Kat & Poppyseed oil \\
\hline Chrome yellow & Aldrich 'lead(II) chromate' & Linseed oil \\
\hline Chrome yellow lemon & $\begin{array}{l}\text { Prepared by Vanessa Otero (Universidade NOVA de Lisboa) according to Winsor and Newton } \\
\text { manufacturing process [52] }\end{array}$ & Linseed oil \\
\hline \multirow[t]{2}{*}{ Eosin } & Home-made based on late 19th and early 20th century recipes & Linseed oil \\
\hline & & Linseed oil + paraffin wax \\
\hline Cochineal & Kremer Pigmente 'carmine naccarat' & Linseed oil \\
\hline Vermilion & Kremer Pigmente 'vermilion' & Linseed oil \\
\hline Red lead & $\begin{array}{l}\text { RCE reference collection } \\
\text { Sikkens verkoop Nederland N.V., Sassenheim }\end{array}$ & Linseed oil \\
\hline Viridian green & Kremer Pigmente 'viridian green' & Linseed oil \\
\hline Emerald green & $\begin{array}{l}\text { RCE reference collection } \\
\text { N.V.Vernis-en Verffabriek Vettewinkel and Zonen }\end{array}$ & Linseed oil \\
\hline Ultramarine blue & Kremer Pigmente, 'ultramarine blue, dark' & Poppyseed oil \\
\hline Cobalt blue & Kremer Pigmente 'cobalt blue medium' & Poppyseed oil \\
\hline Prussian blue & Kremer Pigmente 'Prussian blue LUX' & Poppyseed oil \\
\hline Barium sulphate & Kremer Pigmente 'blanc fixe' & Poppyseed oil \\
\hline Calcium carbonate & Kremer Pigmente 'calcium carbonate' & Poppyseed oil \\
\hline Bone black ${ }^{a}$ & Kremer Pigmente 'bone black' & Linseed oil \\
\hline
\end{tabular}

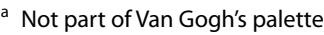

types of chrome yellow in Field with Irises near Arles: almost pure lead chromate $\left(\mathrm{PbCrO}_{4}\right)$, which is medium yellow in color, and a more lemon yellow variety with approximately equal amounts of sulphate to chromate $\left(\mathrm{PbCr}_{0.5} \mathrm{~S}_{0.5} \mathrm{O}_{4}\right){ }^{11}$ For the paint reconstructions lead(II) chromate $\left(\mathrm{PbCrO}_{4}\right)$ was purchased from Aldrich $(\geq 98 \%)$. The lemon chrome yellow with approximately equal amounts of sulphate to chromate was prepared by Vanessa Otero (Universidade NOVA de Lisboa) according to the company manufacturing process of Winsor and Newton (Pr1b_I corresponding to $\mathrm{Pb}[\mathrm{Cr}, \mathrm{S}] \mathrm{O}_{4}$ ) and kindly made available for our research [52].

\section{Pigments taken from the historical pigment collection}

The Cultural Heritage Agency of the Netherlands (RCE) holds a large collection of historical pigments of different origin, which includes many pigments that are no longer available due to their poisonous nature. One of them is emerald green (copper acetoarsenite). The pigment in our collection was produced by the Dutch paint manufacturer N.V. Vernis-en Verffabriek Vettewinkel \& Zonen established in Amsterdam between 1850 and 1970. The pigment was analyzed by means of X-ray diffraction (XRD) which confirmed the presence of copper acetoarsenite.

${ }^{11}$ Possibly a third variety is present as well [44].
The other two pigments taken from the RCE-collection are red lead and lead white, which are both toxic as well. The lead white pigment was produced by the Dutch lead white factory in Schoonhoven de Kat. This company was founded in 1778 and became the largest lead white producing company in West-Europe in 1963 [53], but due to diminishing demand it had to close down in the 1990's. The Schoonhoven company produced lead white according to the Dutch or stack-process whereby lead sheets are first exposed to acetic acid to form lead acetate and subsequently to carbonic acid and warmth, produced by horse manure, resulting in basic lead carbonate (lead white). In the 20th century the procedure was somewhat adjusted for health safety reasons; the horse manure was replaced by coke fire and heating by a steam-boiler [54]. The red lead pigment was produced by the firm 'Sikkens verkoop Nederland N.V', Sassenheim, The Netherlands. $\mathrm{XRD}$-analysis proved the presence of lead tetroxide (red lead).

\section{Pigments purchased from Kremer Pigmente}

The largest group of pigments used in the reconstructions were obtained from the German company Kremer Pigmente. This group includes the pigments zinc white, lead white, synthetic ultramarine blue, Prussian blue, cobalt blue, viridian, vermilion and the extenders calcium carbonate and barium sulphate (Table 4). These pigments and extenders are considered relatively stable and 
therefore their contribution to the color change of Field with Irises near Arles is considered to be small. For some of the pigments Kremer Pigmente offers a wide variety of hues, e.g. nine different cobalt blues are available. A couple of them do not correspond to the cobalt aluminate variety found on Van Gogh's palette (pigment blue 28), but consist of other cobalt-based pigments instead. Three do contain cobalt aluminate; they are called cobalt blue 'turquoise light', 'medium' and 'dark greenish.' 'Medium, having the most neutral hue, was chosen for our paint reconstruction.

\section{Paint manufacture}

In Van Gogh's time, mass-produced machine-ground paints were already available, like those from the firm of LeFranc\&cie [55]. On the other hand, paints were still hand-ground and prepared in small colorman shops that received their powdered pigments from manufacturers [30]. Among these merchants were Julien Tanguy and probably Tasset et L'Hôte who were Van Goghs main suppliers from his Arles period onwards [12]. The way of grinding has both an impact on the consistency and thus handling properties, as well as on the brightness of the paint $[55,56]$. Machine-ground paints were considered too fine, which would result in a loss of substantial consistency and reduced brilliance [57]. This latest effect is due to the fact that with decreasing pigment size the reflection (scattering) of light increases, which might result in a less saturated paint color. In addition, since finely ground pigments need more binding medium, the color of the paint is more affected by the yellowing of the oil as well. Also Van Gogh was aware of the effects of pigment particle sizes and ordered coarser ground paints in order to have paints that were "both fresher and longerlasting" ${ }^{12}$ In our project we had access to a small mechanical grinding glass mill as well as several glass slabs and mullers for grinding by hand. Both methods were explored and it was decided to use the glass slabs and the glass mullers on muscle power because this was probably the method mainly used by Van Gogh's suppliers. Furthermore, this method had the advantage that larger amounts of paint could be made at once than in the

\footnotetext{
${ }^{12}$ Letter 668, to Theo van Gogh, 23 or 24 August 1888 "Would you ask Tasset his opinion on the following question? It seems to me that the more finely a colour is ground, the more it is saturated by oil. Now we're not overfond of oil, that goes without saying. If we painted like Monsieur Gérôme and the other trompe-l'oeil photographic ones, we'd no doubt ask for colours ground very fine. We, on the contrary, don't strongly object to the canvas having a rough look. So if instead of having the colour ground on the stone for God knows how many hours, we grind it just long enough to make it workable, without bothering too much about the fineness of the grain, we'd have colours that were fresher, perhaps darkening less. If he wishes to do a test with the 3 chromes, Veronese, vermilion, orange lead, cobalt, ultramarine, I'm almost certain that at greatly reduced cost I would have colours that were both fresher and longer-lasting".
}

mechanical mill that was to our disposal. Above that the grinding process could be better monitored and adjusted if needed when ground by hand. We did not have the possibility to compare the particle sizes of the reconstruction pigments with those used by Van Gogh, but it might be expected that nowadays pigment particle sizes are somewhat smaller than in the late 19th century. The extent to which this affects the color of the reconstruction paints is unclear; a recent study by Gueli et al. revealed that grinding of pigments, including cobalt blue and viridian green, to sizes ranging from 0 to $75 \mu \mathrm{m}$, does not induce changes detectable by the human eye neither in terms of hue nor in terms of color saturation [58].

The white paints zinc white and lead white were prepared with poppyseed oil being consistent with the identification of this oil in Van Gogh's white paints [17]. Also, the blue paints, synthetic ultramarine blue, Prussian blue and cobalt blue were ground in poppyseed oil, since historical sources and chemical analyses of impressionists' paints indicate that this was common practice [59]. Poppyseed oil does not yellow much with age and is therefore suitable for use in these paints. The other colors were prepared with linseed oil. Two different paints based on eosin pigment ground in linseed oil were prepared: one with and one without the addition of $1.5 \%(\mathrm{w} / \mathrm{w})$ paraffin wax. This additive was identified in Van Gogh's eosin paints and was probably added to improve the consistency of the paint and therewith counteract the consequences of the use of an excess of oil [2, 30, 55]. To prepare the reconstruction paints we added oil to $1 \mathrm{~g}$ of pigment on a glass slab and ground until a good, workable consistency was achieved that would allow for an uniform and smooth application. The average weight percentages of oil in a few paints and the corresponding oil absorption values of the reconstruction pigments are given in Table 5. The calculated oil absorption values of the reconstruction pigments follow the same trend as the oil absorption values given in literature $[60,61]$. However, the amounts of oil used in the reconstruction paints largely exceed the amounts expected based on these values in literature. This might partly be explained by the fact that we were aiming at relative fluid paints. Yet other factors might also play a role: oil absorption values largely depend on pigment particle characteristics, as size and shape, as well as on the paint manufacturing process; paints produced from grinding by hand with a muller may contain considerably more oil than modern machine-ground paints [60]. Moreover, eosin and chrome yellow tube paints that were presumably used by Van Gogh appeared to contain an excess of oil as well [2, 62].

After grinding, the paints were stored in collapsible aluminum tubes. 
Table 5 Average weight percentage of oil in the reconstruction paints, calculated oil absorption values of the reconstruction pigments and oil absorption values reproduced from literature $[60,61]$

\begin{tabular}{|c|c|c|c|c|}
\hline \multirow[t]{2}{*}{ Pigment name } & \multirow[t]{2}{*}{ Binding medium } & \multirow[t]{2}{*}{ Average weight $\%$ of oil (\%) } & \multicolumn{2}{|c|}{ Oil absorption value (wt/100 wt) } \\
\hline & & & Reconstruction pigments & Literature \\
\hline Barium sulphate & Poppyseed oil & 28 & 39 & $13[61]$ \\
\hline Calcium carbonate & Poppyseed oil & 28 & 40 & - \\
\hline Zinc white & Poppyseed oil & 37 & 60 & $10-22[60]$ \\
\hline Eosin & Linseed oil & 37 & 60 & - \\
\hline Ultramarine & Poppyseed oil & 41 & 70 & $28-31[60]$ \\
\hline Bone black & Linseed oil & 48 & 94 & $15-50[60]$ \\
\hline Cobalt blue & Poppyseed oil & 51 & 104 & $\begin{array}{l}18-35[60] \\
37 \pm 5[61]\end{array}$ \\
\hline Prussian blue & Poppyseed oil & 56 & 127 & $40-53[60]$ \\
\hline
\end{tabular}

Besides being able to adjust the particle size and pigment to binder ratio to his own preference, there was another reason why Van Gogh preferred freshly ground paints. Some paints, among others paints based on lake pigments, grow 'fat' during storage which means that they thicken and become tough. This problem was probably also encountered by Van Gogh: in a letter from 5 April 1888 he ordered several paints and wrote that the geranium lake, ordinary lake and carmine should be 'freshly ground, if they're greasy, I'll send them back.' ${ }^{13}$ Interestingly, the same phenomenon was encountered when we reconstructed the cochineal paint. The cochineal pigment was easily ground in linseed oil which resulted in a very dark red, opaque paint. After the cochineal paint was kept in an aluminum tube for a couple of months however, it became very viscous and couldn't be used as such anymore.

For all paints, except lemon chrome yellow, one or two $125 \mathrm{ml}$ tubes of paint were prepared. In total 26 tubes of the 16 different paints were made (Table 4), representing the 15 pigments and extenders-eosin made in twofoldused in Field with Irises near Arles.

\section{Determination of optical characteristics Optical model}

To calculate the optical properties of the paints we use the full non-hiding form of the Kubelka-Munk theory. The basic theory is presented in many textbooks, such as $[63,64]$. Here, we will only summarize the main equations of this model when it is applied to the case of a transparent paint applied on a substrate. In KubelkaMunk theory, the optical properties of a paint are described by two parameters, the absorption $K$ and scattering $S$ parameters. Both parameters are a function of

${ }^{13}$ Letter 593, From Vincent van Gogh to Theo van Gogh, Arles, on or about Thursday, 5 April 1888. wavelength. Using Eq. 1 we can then calculate the theoretical reflectance $R_{t}$ of the paint [65]:

$$
\begin{aligned}
R_{t}= & \frac{(a+b)\left(a-b-R_{g}\right) \exp (-2 b S D)-\left(a+b-R_{g}\right)(a-b)}{\left(a-b-R_{g}\right) \exp (-2 b S D)-\left(a+b-R_{g}\right)} \\
& a=1+\frac{K}{S} \\
b & =\sqrt{a^{2}-1}
\end{aligned}
$$

where $R_{g}$ is the reflectance of the substrate under the paint layer, $R_{t}$ is the theoretical reflectance of the paint including the influence from the substrate, and $D$ is the thickness of the paint layer. In Eq. 1, the influence of light reflection at the paint-air interface is not accounted for. This is achieved by using the Saunderson correction with the following expression [63]:

$$
R_{m}=\alpha k_{1}+\frac{\left(1-k_{1}\right)\left(1-k_{2}\right) R_{t}}{1-k_{2} R_{t}}
$$

where $R_{m}$ is the reflectance predicted to be measured.

In the current investigation, the reflectance data were measured with an integrating sphere spectrophotometer (Minolta CM-2600d) in its specular included mode. For that case, we used values for the Saunderson parameters that are known to be realistic for paint systems, with $k_{1}=0.04$ and $k_{2}=0.49$ [63]. For Specular Component Included measurement data like we use here, the value of parameter $\alpha=1$. In order to calculate the reflectance factor of a mixture of pigments, the commonly used relationship proposed originally by Duncan is used:

$$
\left(\frac{K}{S}\right)_{\text {mixture }}=\frac{c_{1} K_{1}+c_{2} K_{2}+\cdots+c_{N} K_{N}}{c_{1} S_{1}+c_{2} S_{2}+\cdots+c_{N} S_{N}}
$$


where $N$ is the total number of pigments in the mixture, $c_{i}$ is the weight concentration of pigment number $i$, and $K_{i}$ and $S_{i}$ are the Kubelka-Munk $K$ and $S$ parameters for pigment number $i[64,66]$.

\section{Spectral properties of the reconstructed paint mixtures}

For an accurate determination of optical parameters, the reconstructed paints were mixed with different percentages of bone black and zinc white paint. Figure $3 \mathrm{a}, \mathrm{b}$ give an overview of these mixtures. In Field with Irises near Arles no black pigment was identified, but a study of Van Gogh's works from the same period has shown that he did use bone black sporadically [17]. Therefore we added bone black to the set of paints, only to be able to estimate Kubelka-Munk scattering (and absorption) coefficients with higher accuracy. For the white base paint, we preferred to use zinc white, that Van Gogh used in the sky of Field with Irises near Arles, above lead white-used in the field-because it provides a cool, brilliant white and is non-toxic.

The basic mixing scheme that we used was to have mixtures with zinc white base paint in 90:10 and 50:50 ratios, and with bone black paint in 99:1 and 90:10 ratios. However, depending on the pigment in some cases other ratios were found to be more suitable. For example, for deeply colored paints the amount of black pigment needed to be reduced to prevent mixtures to become completely black, which would eliminate any added value to the determination of optical parameters. For the intense colored Prussian blue, which is very dark blue-almost black-in oil paint, we found that mixing with black was not meaningful at all. On the other hand, for all white pigments and fillers in this study, a different scheme of mixtures had to be used. These were mixed in 90:10 ratios with cochineal, viridian and cobalt blue paints, and with bone black in several ratios (Fig. 3b). All mixtures were applied on a standardized black-white chart from BYK-Gardner, using a block operator to create a relatively uniform layer of $100 \mu \mathrm{m}$ thickness. We let the paints dry in air. Finally, we measured the reflectance spectrum for each mixture on both black and white substrate using a Konica-Minolta 2600D diffuse sphere (d/8) spectrophotometer. We used this instrument in Specular Component Included mode, to ensure good alignment with other $d / 8$ spectrophotometers. To avoid problems with fluorescence, illumination was cut off below $400 \mathrm{~nm}$.

\section{Determining the optical parameters}

Based on all reflectance data obtained for the paint mixtures, the Kubelka-Munk $\mathrm{K}$ and $\mathrm{S}$ values were determined for each pigment as follows [67]. We first investigated pigment zinc white. We obtained reflectance data of this pigment applied as pure and for four mixtures with bone black, in various ratios. For each wavelength we optimized the four unknown parameters (K and $\mathrm{S}$ for both pigments), based on ten reflectance values (five mixtures including the pure zinc white paint, each applied over two different substrates). Considering only the range of wavelengths between 400 and $700 \mathrm{~nm}$ most relevant for visual appearance, we used $10 \mathrm{~nm}$ resolution in these calculations. This resulted in 31 different wavelengths to consider. We performed the optimizations for all wavelengths simultaneously, which is possible since $\mathrm{K}$ and $\mathrm{S}$ values for different wavelengths are determined independently from each other. We used the average deviation in reflectance value over all wavelengths as optimization criterion. The same optimization criterion will be used for the other pigments as well. Figure 4 shows the reflectance values of all four mixtures, as measured over black (dashed lines) and over white substrate (solid lines). For wavelengths at which the lines overlap the corresponding mixture is opaque. With optimized $\mathrm{K}$ and $\mathrm{S}$ values for zinc white and bone black, as just described, the predicted reflectance values are given in Fig. 4. Filled markers refer to predicted reflectances over white substrate, and open markers do the same for black substrate. Figure 4a shows that all eight reflectance curves (4 mixtures over 2 different substrates) are well described by the optimized $\mathrm{K}$ and $\mathrm{S}$ values. From Fig. $4 \mathrm{~b}$ it is clear that the optimized values for the scattering parameter $\mathrm{S}$ are much larger than those for the absorption parameter $\mathrm{K}$. This is obviously as expected for a white pigment such as zinc white.

Next, we investigated reconstruction paint cochineal. For this paint, Fig. 5 shows the data for the five mixtures that were available: one consisting of pure cochineal, two mixtures with zinc white and two mixtures with bone black paint. Since values for the $\mathrm{K}$ and $\mathrm{S}$ parameters of zinc white had already been determined in the previous step, this led to an optimization for each wavelength of four parameters (K and S for cochineal and bone black) using ten reflectance values (five mixtures over two different substrates). In Fig. 5a we show the reflectance values for all mixtures, over both substrates. These are shown both for measured reflectance values and for calculated reflectance values, using the optimized $\mathrm{K}$ and $\mathrm{S}$ values for cochineal and bone black. According to Fig. 5a, the measured reflectance values are reproduced well by the Kubelka-Munk equation.

Figure $5 \mathrm{~b}$ shows the $\mathrm{K}$ and $\mathrm{S}$ values for reconstruction paint cochineal after optimization. For most wavelengths, the calculated values for the scattering parameter $\mathrm{S}$ are much smaller (and effectively zero) than for the absorption parameter $\mathrm{K}$. This is consistent with the translucent nature of this lake pigment, and we will find the same phenomenon for eosin. The large values for absorption 

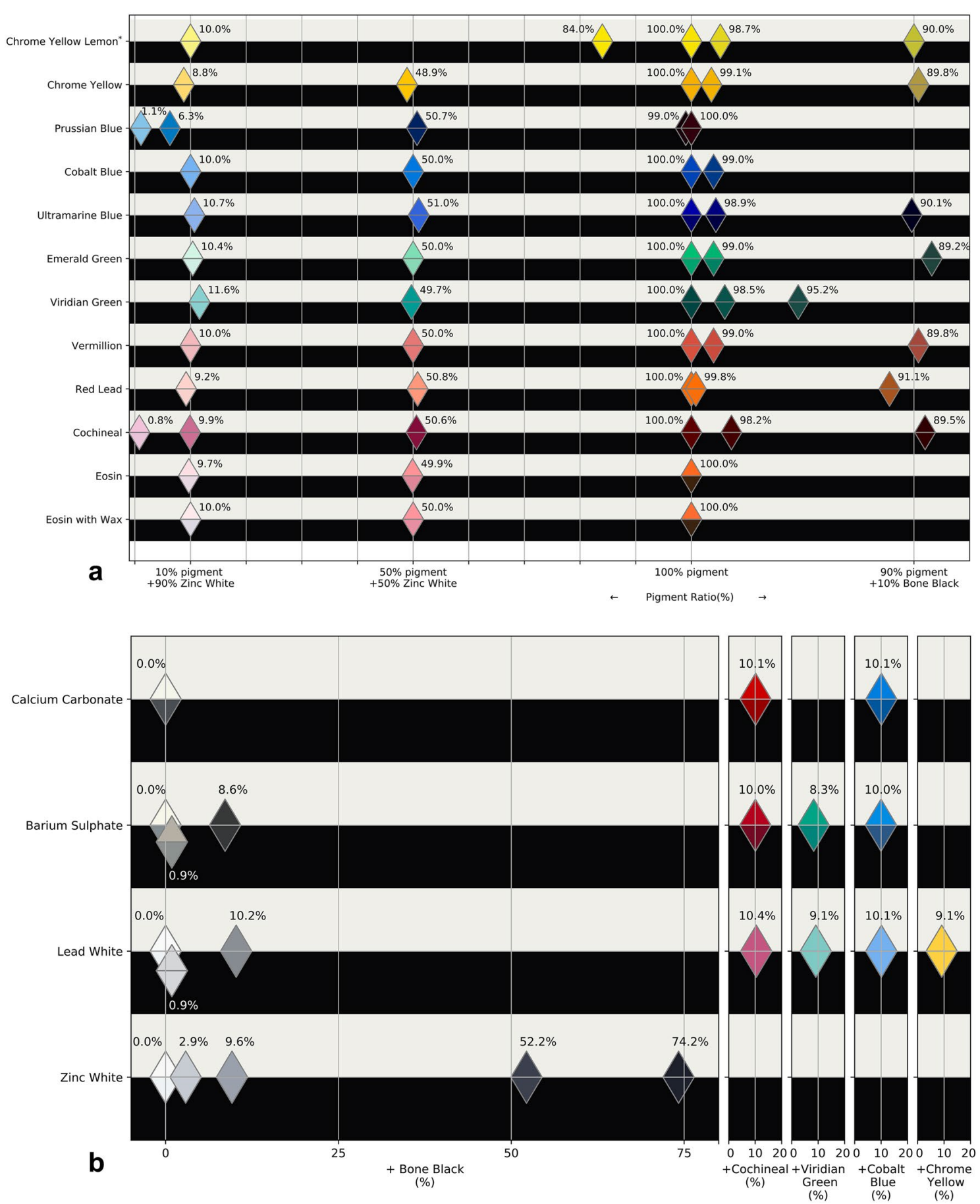

Fig. 3 a Mixtures of palette pigments blended with zinc white and bone black and $\mathbf{b}$ additional mixtures of white pigments and extenders. The percentages in the figure give the actual paint compositions as prepared for this study 

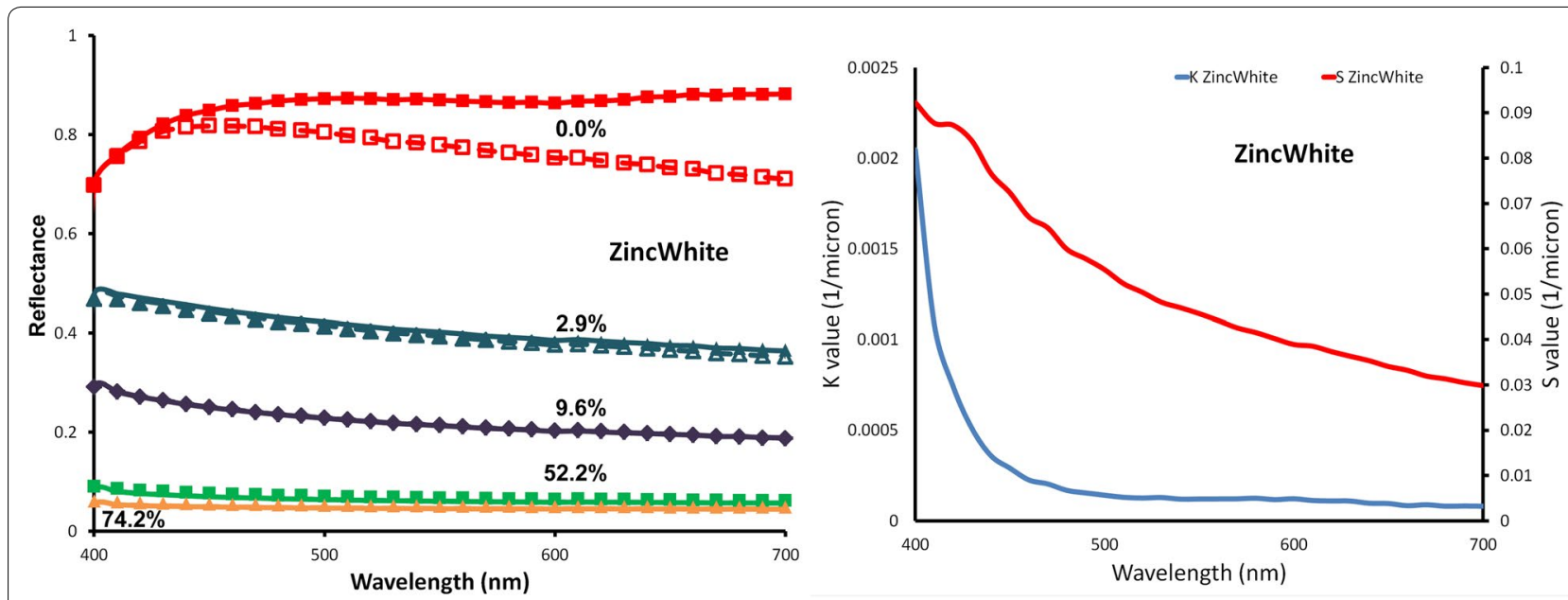

Fig. 4 Estimation of K\&S values for pigments zinc white and bone black. a Reflectance curves as measured over black (dashed lines) and over white substrate (solid lines), where percentages refer to concentrations of bone black. These are compared to Kubelka-Munk predictions for the various mixtures, both over black (open markers) and over white substrate (filled markers). b Optimized values for K and S parameters
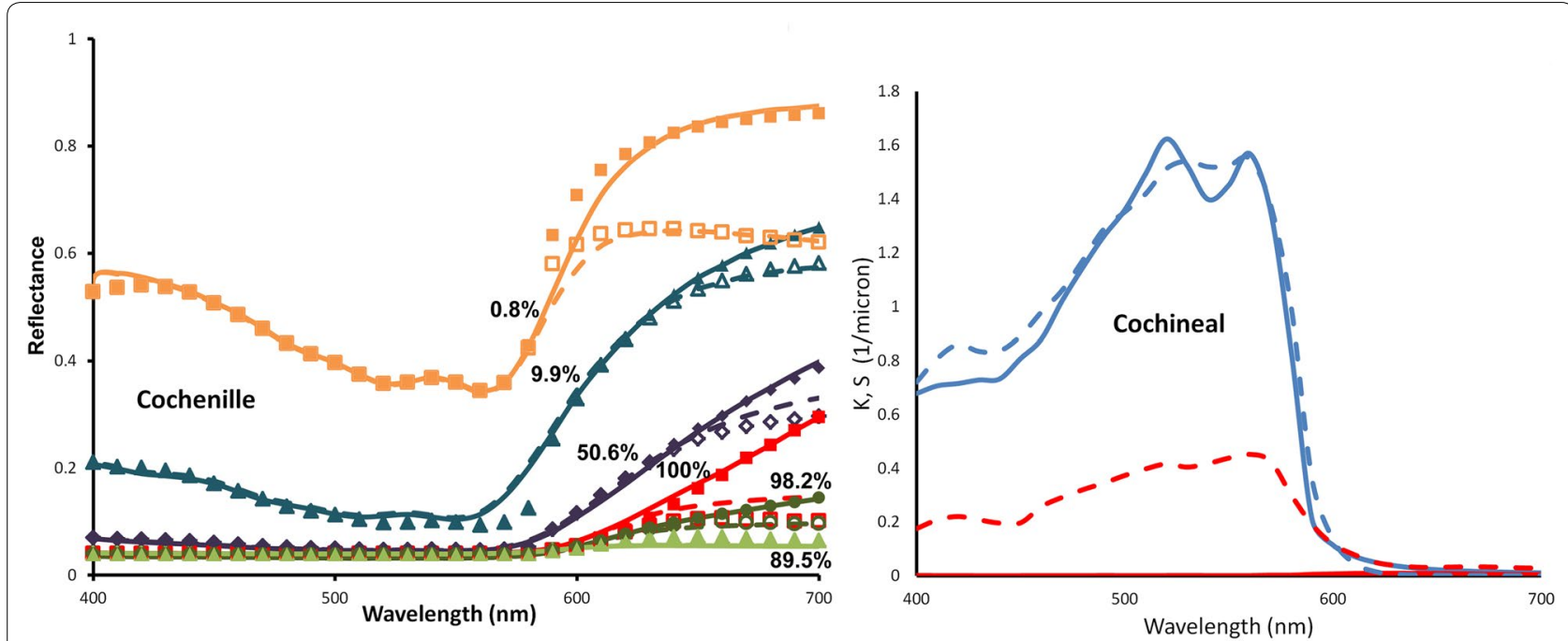

Fig. 5 a Reflectance values for mixtures of reconstruction paint cochineal, as measured and as calculated with the model. Notation similar to Fig. 4; percentages refer to mixtures described in Fig. 3. b Optimized K (blue lines) and S values (red lines) for cochineal (solid lines), compared to values published by Takei and Yoshida (dashed lines) [61]. Optimized S values for cochineal are effectively zero

explains the intense color of eosin and cochineal. The combination of these features explains their use as a glaze: they produce intense bright red colors when thinly applied over a light substrate. When applied as a thick layer however, the colors of these lake pigments become very dark, and hence they can be used in dark outlines or shadows.

Figure $5 \mathrm{~b}$ also shows $\mathrm{K}$ and $\mathrm{S}$ values of cochineal that have been published by Takei and Yoshida [68]. Those results also show scattering parameter values that are much larger than the absorption values, although the difference is smaller than in the values found in the present study. The shape of the absorption curve as found by optimization here is very similar to the results from Takei and Yoshida. Since the results from Takei and Yoshida do not have a dimension, it is not possible to compare them in an absolute sense with the values that we found here. This will also be the case for the other pigments for which we found earlier publications on $\mathrm{K}$ and $\mathrm{S}$ values.

For eosin we followed a similar analysis as just described for zinc white and cochineal. Figure 6 shows the $\mathrm{K}$ and $\mathrm{S}$ values that were found in this way. For most 


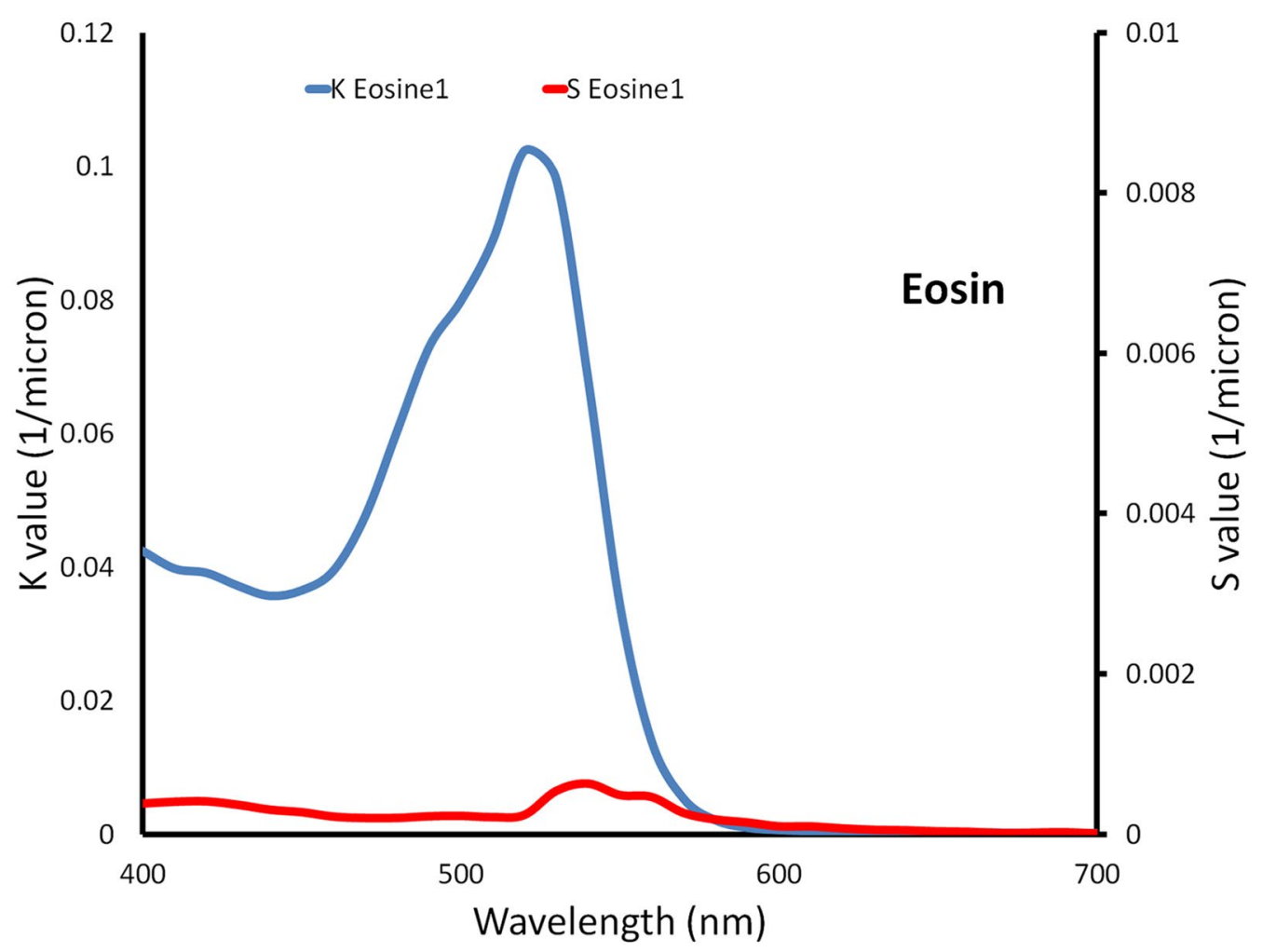

Fig. 6 Calculated Kubelka-Munk K (solid blue line) and S values (solid red line) for reconstruction paint eosin

wavelengths, the calculated values for the scattering parameter $\mathrm{S}$ are indeed more than two orders of magnitude smaller than for the absorption parameter $\mathrm{K}$, which is consistent with its origin as a lake pigment.

Two different hues of chrome yellow paint were identified in Field with Irises near Arles and therefore included in the reconstructions: chrome yellow and chrome yellow lemon. SEM-EDX-analyses showed that Van Gogh's chrome yellow paint contains small amounts of calcium carbonate in addition (around 3.4\% in weight). We treated calcium carbonate as a separate reconstruction paint and formulated the chrome yellow reconstruction paint without any calcium carbonate. After determining the optical properties of both paints with two-constant Kubelka-Munk theory, we calculated the theoretical $\mathrm{K}$ and $\mathrm{S}$ values of this mixture of two components by applying Duncan's theory for pigment mixtures (Eq. 3). When calculating the Pigment Concentration Maps for the painting in our previous investigation, we had already found the need to distinguish two different types of chrome yellow paint [14]. For those two types, we can calculate the reflectance if they would appear in unmixed form on the painting. These reflectance values are shown as solid lines in Fig. 7a. The reflectance curve of the chrome yellow type that was found in the yellow-brown dots in the foreground of the painting (dashed red line) is seen to be shifted to the right with respect to the values (dashed blue line) for the lighter type of chrome yellow, which is found mainly in the field area. This shift results in a more reddish color of the chrome yellow in the dots in the foreground. Figure $7 \mathrm{a}$ also shows the reflectance curves that we have measured on white substrate for the two reconstruction paints (both in unmixed form) chrome yellow lemon (blue solid line in Fig. 7a) and chrome yellow (red solid line). For these two reconstruction paints the reflectance values show a similar shift, indicating that they can indeed be used to represent the unaged form of the two types of this paint that have been identified in the painting. We note that due to darkening the reflectance values of the aged paints are smaller than those of the reconstruction paints.

In Fig. $7 \mathrm{~b}$ we show the values of the absorption $\mathrm{K}$ and scattering $\mathrm{S}$ parameters of chrome yellow and chrome yellow lemon, optimized with the same procedure as already described for other pigments, and after including calcium carbonate in the calculation for the chrome yellow reconstruction paint. These values are compared to values published by Levinson et al. for chrome yellow $\left(\mathrm{PbCrO}_{4}\right)$ [69]. Indeed, the values for chrome yellow agree best with those published by Levinson et al. 

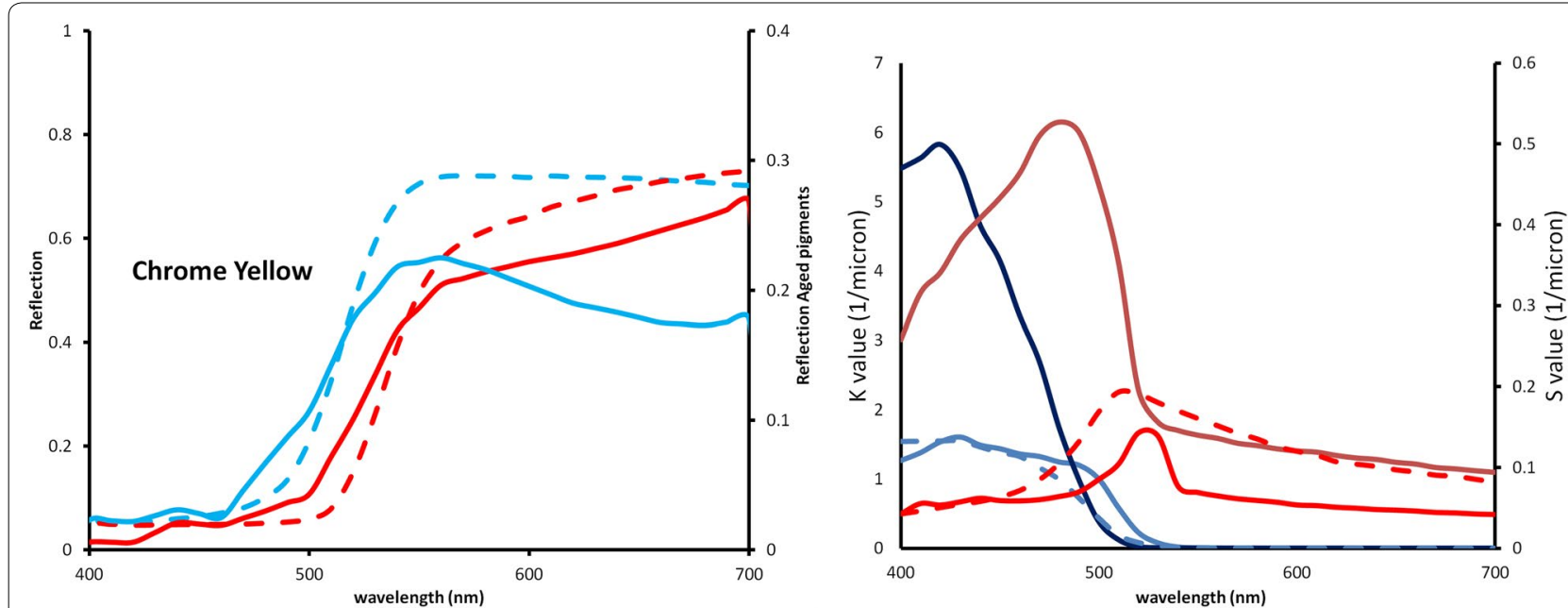

Fig. 7 a For the reconstruction paints of chrome yellow, measured reflectances of pure paint over white substrate are shown as dashed curves for chrome yellow lemon (blue) and chrome yellow (red). Solid lines show calculated reflectance of two types of chrome yellow as found in aged state on Field with Irises near Arles: chrome yellow as found in the field (blue), and as found in the yellow-brown dots (red). b Calculated Kubelka-Munk $\mathrm{K}$ (solid blue lines) and S values (solid red lines) for reconstruction paints chrome yellow (lighter colored line) and chrome yellow lemon (darker colored line). Dashed lines refer to published results from Levinson et al. [69]

SEM-EDX analysis showed that Van Gogh used two types of emerald green paint in Field with Irises near Arles: one pure emerald green paint and one paint that contains emerald green mixed with barium sulphate in a ratio of c. 2:1 in weight. We treated the barium sulphate additive as a separate reconstruction paint, similar to what we described for the calcium carbonate additive. The emerald green to barium sulphate ratio in the paint could be theoretically confirmed by calculating the values of the Kubelka-Munk $\mathrm{K}$ and $\mathrm{S}$ parameters for different mixtures of emerald green and barium sulphate.
We compared the resulting $\mathrm{K}$ and $\mathrm{S}$ curves with the corresponding curves calculated before for (aged) emerald green paint on the painting [14]. After normalization by dividing through the values of the $S$ curve for base paint white, the resulting $\mathrm{K}$ and $\mathrm{S}$ curves showed best agreement if barium sulphate accounts for 30 to $50 \%$ of the emerald green paint (see Fig. 8). This is in good agreement with the experimental estimation of $33 \%$.

We used the same procedure for all other pigments. This led to good optimization results for most pigments, similar to the other examples. As an illustration of a
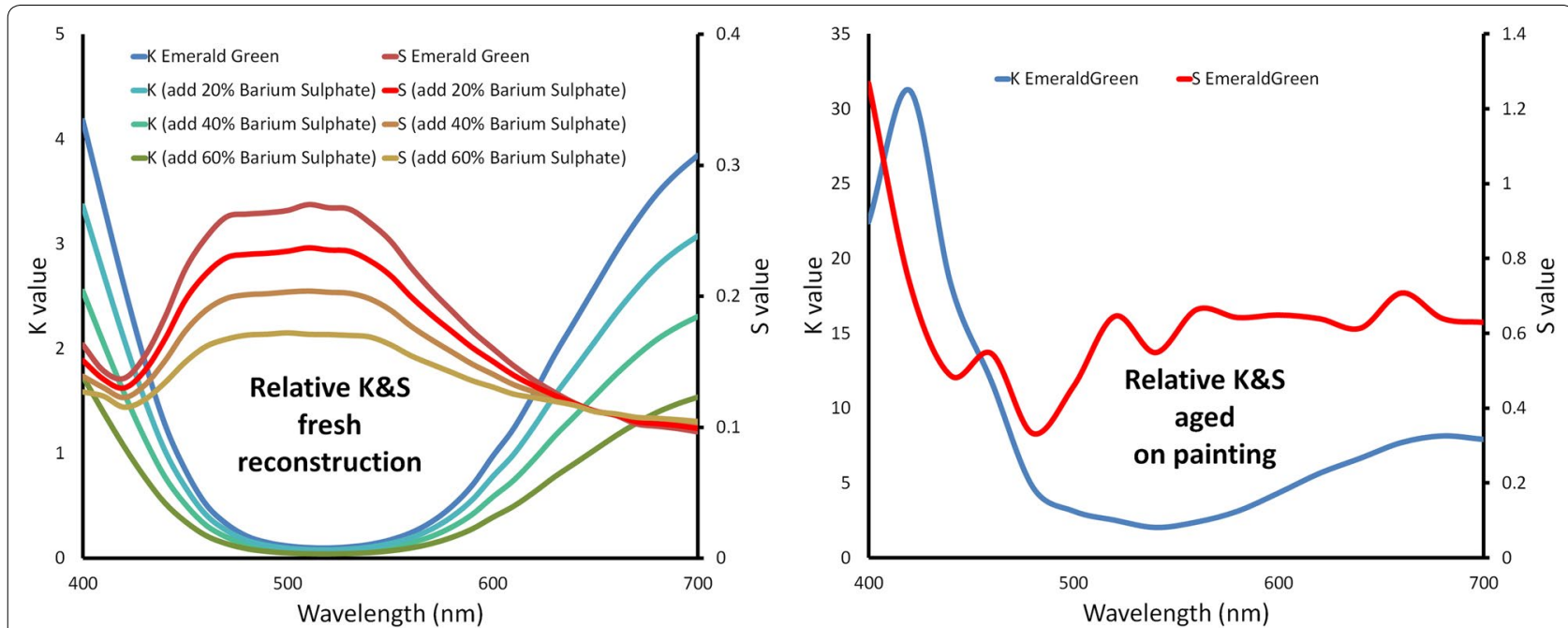

Fig. 8 a Kubelka-Munk K and S values calculated for emerald green reconstruction paint, assuming various amounts of barium sulphate to be mixed in. b Kubelka-Munk K and S values for emerald green as determined from aged emerald green pigment on Field with Irises near Arles [14] 
pigment where this was not the case however, we use the example of ultramarine blue. This turned out to represent the most difficult pigment for which we optimized values of the Kubelka-Munk parameters. We only found a satisfactory match between calculated and measured reflectance values if we made the additional assumption that the concentrations of mixtures for this pigment deviated from the values measured with a weight balance. As an example, the largest deviation was found for the mixture that was supposed to contain $51 \%$ of ultramarine blue. Optimization of Kubelka-Munk reflectance values improved considerably when we assume the actual percentage was only $39 \%$. We have no conclusive explanation why this concentration might have been different from the weighed value. Perhaps the grinding, dispersion or mixing of the pigment was not successful in spite of all our efforts. Figure $9 \mathrm{~b}$ shows the resulting $\mathrm{K}$ and $\mathrm{S}$ values of the ultramarine blue paint, in comparison to values published by Latour et al. of ultramarine pigment in acrylic medium [64]. In spite of the difficult optimization and the assumption we had to make, the resulting estimations of Kubelka-Munk K and S values agree reasonably well with the published values. Figure 9a shows the reflectance values for all mixtures on both substrates, as measured on the samples and as calculated from Kubelka-Munk theory. This figure shows that the quality of the theoretical predictions is reasonable, but less good than for the mixtures of paints described above.

For all remaining paints not yet considered here, the results of $\mathrm{K}$ and $\mathrm{S}$ optimizations can be found in Fig. 10.

\section{Conclusions}

The full reconstruction of the tube paints that Van Gogh used to paint Field with Irises near Arles provided us with a glimpse of his bright, original palette. Van Gogh combined the paints on his palette in all sorts of mixtures on his painting. In order to be able to calculate the colours of these different paint mixtures, we successfully determined the optical parameters (K and $\mathrm{S}$ ) of the reconstructed paints, which allowed us to digitally visualize the original colours of Field with Irises near Arles. This method can equally be applied to others works by Van Gogh that were painted with the same palette. Since many of Van Gogh's contemporaries used similar tube paints, or even purchased their paints from the same supplier as Van Gogh did, this application is however not

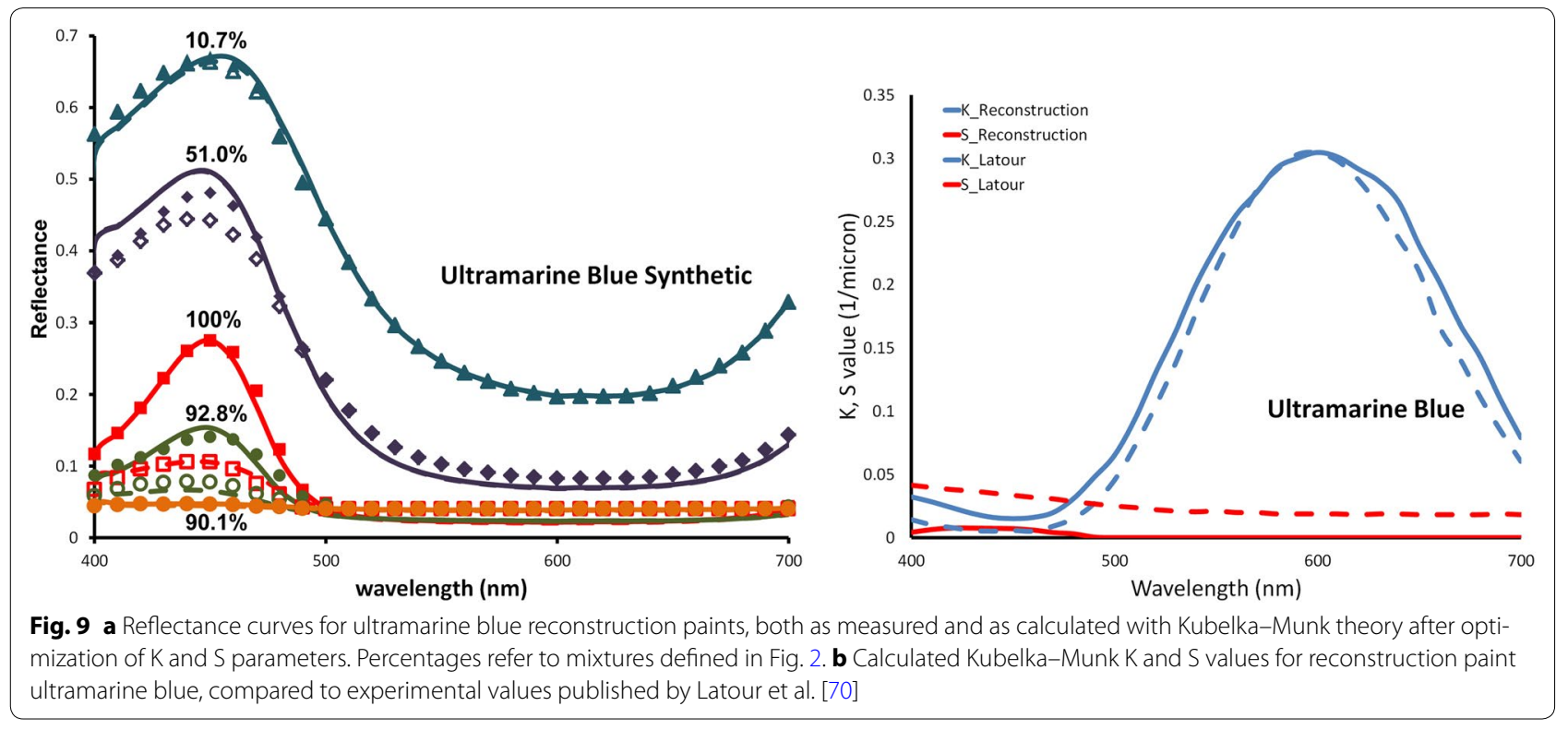




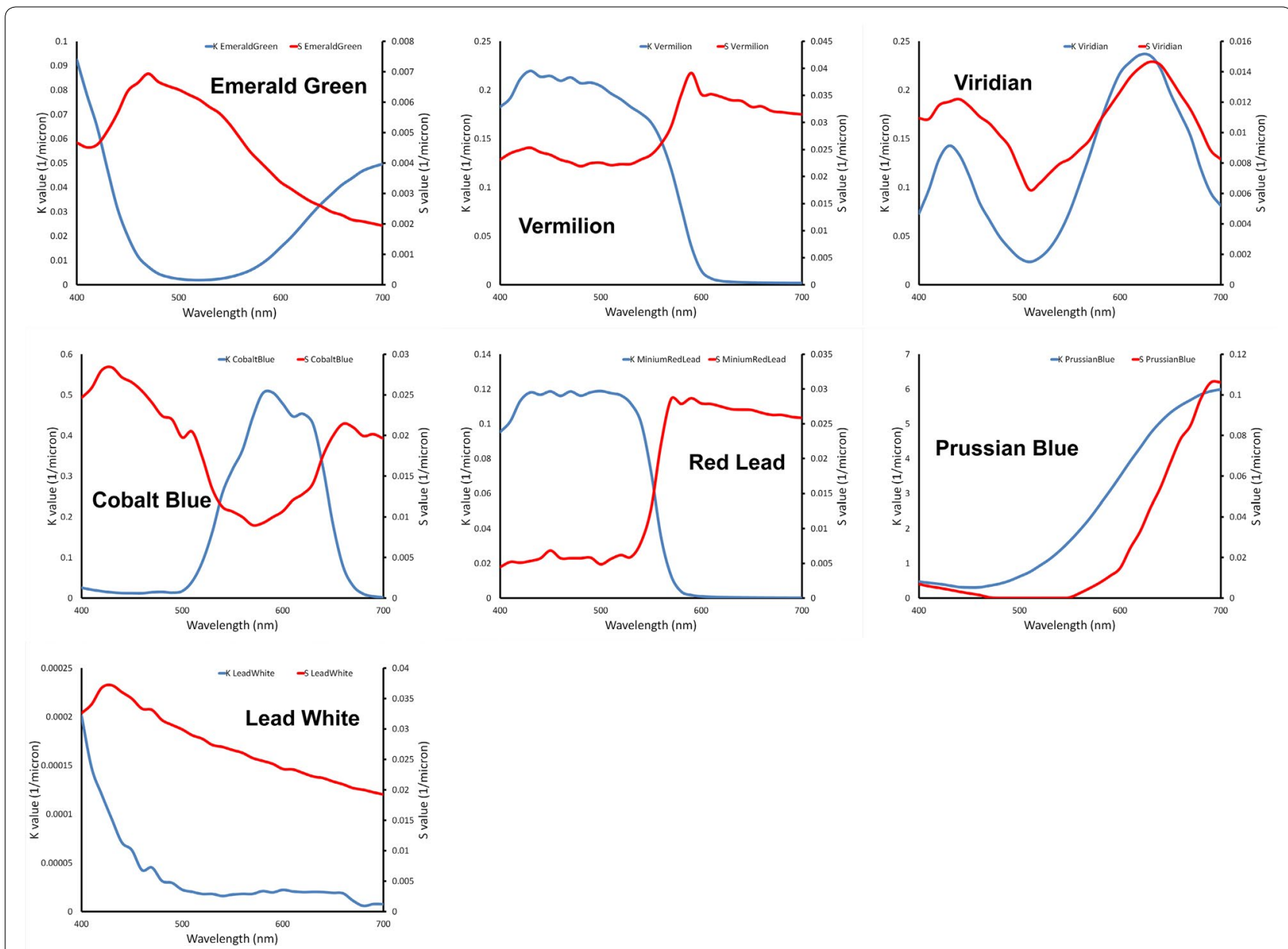

Fig. 10 Optimized $\mathrm{K}$ and $\mathrm{S}$ values for remaining paints

confined to Van Gogh's paintings alone. Furthermore, the set of parameters can easily be extended by reconstructing other paints, leading to an even broader application.

\section{Authors' contributions}

MG supervised the reconstruction of Van Gogh's paints, selected the reconstruction pigments and assisted pigment and paint production. She analyzed the reconstructed organic red pigments with OM, SEM-EDX and micro-VISspectrometry. ANPG produced the organic red pigments and linseed oils. He made the paint reconstructions, mixed the paints and applied them on opacity charts. He performed UHPLC-analysis of the organic red pigments reconstructions and chemical analysis of the oils. FL performed spectral reflectance measurements. EH conducted full technical investigation and conservation treatment of Field with Irises near Arles. EK designed the set of paint mixtures (Fig. 3a, b) and determined the optical properties with the Kubelka-Munk model. All authors read and approved the final manuscript.

\section{Author details}

${ }^{1}$ Cultural Heritage Agency of the Netherlands (RCE), Hobbemastraat 22, 1071 ZC Amsterdam, The Netherlands. ${ }^{2}$ Programme Conservation and Restoration of Cultural Heritage, University of Amsterdam, Johannes Vermeerplein 1, 1071 DV Amsterdam, The Netherlands. ${ }^{3}$ AkzoNobel Performance Coatings, Color Research, Rijksstraatweg 31, 2171 AJ Sassenheim, The Netherlands.

\section{Acknowledgements}

We are grateful to the Van Gogh Museum for the opportunity to investigate Field with Irises near Arles. Leslie Carlyle, Diogo Sanchez and Sara Babo are thanked for their hospitality and help using the hydraulic press at the Universidade NOVA de Lisboa. We are also indebted to Leslie Carlyle and Vanessa Otero from this University for sharing their self-produced chrome yellow pigments. Hayo de Boer (independent researcher) generously shared his knowledge on historic oil production. Indra Kneepkens (University of Amsterdam), Nathalie de Vries and Eric Jonker (interns) are thanked for their contribution to the acid value and iodine value determinations. Indra also worked with us on the experiments with linseed oil. We thank the miller team of windmill't Pink who helped with expressing the oil (André Koopal, Kevin Bus, Christiaan Smit, Ranko Veuger and Abel). We are indebted to Jo Kirby and Maarten van Bommel for sharing their knowledge and giving advice about historical pigment production. We thank Lucas Mantel who helped us with paint making and application of the paints. Finally we wish to thank our colleagues from the RCE: Birgit Reissland, Wouter Pfeiffer, Klaas Jan van den Berg, Luc Megens and Han Neevel for sharing their expertise and their support during the project.

\section{Ethics approval and consent to participate}

Not applicable.

\section{Competing interests}

The authors declare that they have no competing interests.

Availability of data and materials

Data are available upon request to the corresponding authors. 


\section{Funding}

The research reported in this paper is performed as part of the REVIGO project, supported by the Netherlands Organization for Scientific Research (NWO; Grant 323.54.004) in the context of the Science4Arts research program.

\section{Publisher's Note}

Springer Nature remains neutral with regard to jurisdictional claims in published maps and institutional affiliations.

Received: 19 January 2018 Accepted: 3 March 2018

Published online: 20 March 2018

\section{References}

1. van Bommel M, Geldof M, Hendriks E. An investigation of organic red pigments used in paintings by Vincent van Gogh (November 1885 to February 1888). ArtMatters Neth Tech Stud Art. 2005;3:111-37.

2. Geldof M, de Keijzer M, van Bommel M, Pilz K, Salvant J, van Keulen H, et al. Van Gogh's geranium lake. In: Vellekoop M, Geldof M, Hendriks E, Jansen L, de Tagle A, editors. Van Gogh's studio practice. Brussels: Mercatorfonds; 2013. p. 268-89.

3. Burnstock A, Lanfear I, Berg KJ van den, Carlyle L, Clarke M, Hendriks E, et al. Comparison of the fading and surface deterioration of red lake pigments in six paintings by Vincent van Gogh with artificially aged paint reconstructions. In: Vergier I, editor. In: Proceedings of the 14th triennial meeting of the ICOM committee for conservation meeting in Den Haag, preprint book I, vol. 466. London: James and James; 2005. p. 459.

4. Calorin P. Colour fading in Van Gogh and Gauguin. In: Peres C, Hoyle M, van Tilborgh L, editors. A closer look, technical and art-historical studies on works by van Gogh and Gauguin. Zwolle: Waanders Publishers; 1991

5. Rioux J. The discoloration of pinks and purples in Van Gogh's paintings from Auvers. In: Distel A, Stein S, Palais G, editors. Cézanne to Van Gogh: the collection of doctor Gachet. Amsterdam: Van Gogh Museum Amsterdam, Metropolitan Museum of Art; 1999. p. 104-13.

6. Centeno SA, Hale C, Carò F, Cesaratto A, Shibayama N, Delaney J, et al. Van Gogh's irises and roses: the contribution of chemical analyses and imaging to the assessment of color changes in the red lake pigments. Herit Sci. 2017:5:18

7. Hendriks E. "Paintings fade like flowers": consequences of colour change in paintings by Vincent van Gogh'. In: proceedings of the ICON painting group conference, appearances and reality: examining colour change in paintings, Tate Britain. London: Archetype; 2016. p. 39-51.

8. Berns RS, Byrns S, Casadio F, Fiedler I, Gallagher C, Imai FH, et al. Rejuvenating the color palette of Georges Seurat's a sunday on la grande jatte 1884: a simulation. Color Res Appl. 2006:31:278-93.

9. Berns RS. Color science for the visual arts: a guide for conservators, curators and the curious. Los Angeles: Getty Publications; 2016. p. 140-6.

10. Delaney JK, Zeibel JG, Thoury M, Littleton R, Palmer M, Morales KM, et al. Visible and infrared imaging spectroscopy of Picasso's harlequin musician: mapping and identification of artist materials in situ. Appl Spectrosc. 2010;64:584-94

11. Vellekoop M, Geldof M, Hendriks E, Jansen L, de Tagle A, editors. Van Gogh's studio practice. Brussels: Mercatorfonds; 2013.

12. Hendriks E, van Tilborgh L. Vincent van Gogh paintings, Antwerp and Paris 1885-1888, vol. 2. Amsterdam: Van Gogh Museum and Waanders; 2011.

13. Kirchner E, van der Lans I, Ligterink F, Hendriks E, Delaney J. Digitally reconstructing Van Gogh's field with Irises near Arles part 1: Varnish. Color Res Appl. 2017. https://doi.org/10.1002/col.22162.

14. Kirchner E, van der Lans I, Ligterink F, Geldof M, Ness Proano Gaibor A, Hendriks E, et al. Digitally reconstructing Van Gogh's field with Irises nea Arles, part 2: pigment concentration maps. Color Res Appl. 2017. https:// doi.org/10.1002/col.22164.

15. Kirchner E, van der Lans I, Ligterink F, Geldof M, Proano Gaibor AN, Meedendorp T, Pilz K, Hendriks E. Digitally reconstructing Van Gogh's field with Irises near Arles part 3: determining the original colors. Color Res Appl. 2017. https://doi.org/10.1002/col.22197.
16. Geldof M, Megens L. Van Gogh's Dutch palette. In: Vellekoop M, Hendriks E, Jansen L, Geldof M, de Tagle A, editors. Van Gogh's Studio Practice. Brussels: Van Gogh Museum, Mercatorfonds, distributed by Yale University Press; 2013. p. 226-38.

17. Geldof M, Megens L, Salvant J. Van Gogh's palette in Arles, Saint-Rémy and Auvers-sur-Oise. In: Vellekoop M, Hendriks E, Jansen L, Geldof M, de Tagle A, editors. Van Gogh's Studio Practice. Brussels: Van Gogh Museum, Mercatorfonds, distributed by Yale University Press; 2013. p. 238-56.

18. Carlyle L, Witlox M. Historically accurate reconstructions of artists' oil painting materials. Tate Papers; 2007

19. Carlyle L. Historically accurate reconstructions of oil painters' materials. An overview of the hart project 2002-2005. In: Boon JJ, Ferreira ES, editors. Reporting highlights of the De Mayerne Programme. The Hague: NWO; 2006. p. 63-77.

20. Kirby J. The reconstruction of late 19th century French red lake pigments. In: Clarke M, Townsend J, Stijnman A, editors. Art of the past: sources and reconstructions. In: Proceedings of the first symposium of the art technological source research study group, Archetype; 2005. p. 69-77.

21. Mayer R. The Artist's handbook. New York: Viking Press; 1970. p. 175.

22. Gettens RJ, Stout CL. Painting materials. New York: Van Nostrand; 1952. p. 42.

23. Rubens PP, Gachet E. Lettres Inédites de Pierre-Paul Rubens (1840). Whitefish: Kessinger Publishing; 2010. p. 234.

24. Muckley WJ. A handbook for painters and art students on the character, nature, and use of colours, their permanent, or fugitive qualities, and the vehicles proper to employ: with an appendix giving permanent hues and tints: also short remarks on the practice of painting in oil and water colours, 4th edn. London: Baillière, Tindall and Cox; 1893. p. 70-1.

25. Lawrence GHM. The term and category of cultivar. J Baileya. 1955;3:177-81

26. Stanislav F. Über Öle und Lackfirnisse. Technische Mitteilungen für Malerei. 1887;09(36):87-8

27. Zechmeister L. Über Öle und Lackfirnisse. Technische Mitteilungen für Malerei. 1887;10(38):97

28. Thalmann F. Die Fette, Öle und Wachsarten. Ihre Gewinnung und Eigenschaften. Wien-Leipzig: A. Hartlebens Verlag; 1910.

29. Shahidi F, editor. Bailey's industrial oil and fat products. Edible oil and fat products, vol. 5. 6th ed. Hoboken: Processing Technologies; 2005.

30. Carlyle L. The artist's assistant: Oil painting instruction manuals and handbooks in Britain 1800-1900; with reference to selected 18th-century sources. London: Archetype; 2001

31. Meurs A, Boer M den, Coenraads M, Dwarswaard M. De OlieNoot. 2002-2007. http://www.olieslagersgilde.nl/index.html. Accessed 10 Dec 2017.

32. Boorsma P. Over molens der familie Honig. De Zaanlander: Bijzonderheden betreffende molen der familie Honig; 1939.

33. De Theuninck A. laatste olieslager van West-Vlaanderen op de praatstoel. Molenecho's. 1995:23:3.

34. Kneepkens I. Thick and Clear as a Beautiful Crystal: The preparation of sun-thickened linseed oil and its influence on the properties of late medieval paints. ArtMatters (to be submitted).

35. Technical data Alberdingk linseed oil. http://www.alberdingk-boley.de/ en/products/technicaldata/cat2/linseed-oil-and-castor-oil.html. Accessed 5 Dec 2017.

36. Irish Statutory Instruments. Standard specification (Linseed Oil For Paints) Order. 1949;159. http://www.irishstatutebook.ie/eli/1949/si/159/made/ en/print. Accessed 10 Dec 2017.

37. van Dam EP, van den Berg KJ, Proano Gaibor AN, van Bommel M. Analysis of triglyceride degradation products in drying oils and oil paints using LC-ESI-MS. Int J Mass Spectrom. 2017;413:33-42. https://doi. org/10.1016/j.ijms.2016.09.004.

38. Christie WW. The positional distributions of fatty acids in triglycerides. In: Hamilton Rossell RJB, editor. Anal. oils fat. London: Elsevier Applied Science; 1986. p. 313-39.

39. Mills JS. The gas chromatographic examination of paint media. Part I. Fatty acid composition and identification of dried oil films. Stud Conserv. 1966;11:92-107.

40. Tingry PF. The Painter and Varnisher's Guide. London: printed for G. Kearsley, by J. Taylor; 1808.

41. Kumarathasan R. Autoxidation and yellowing of methyl linolenate. Prog Lipid Res. 1992;31:109-26. 
42. Mallégol J, Lemaire J, Gardette J. Yellowing of oil-based paints. Stud Conserv. 2001;46:121-31.

43. Privett OS, Blank ML, Covell JB, Lundberg WO. Yellowing of oil films. J Am Oil Chem Soc. 1961;38:22-7.

44. Geldof M. Haswell R. SEM-WDX investigation of chrome yellow in Field with Irises near Arles. Micro Chim Acta. 2018 (to be submitted).

45. Hendriks E, Jansen L, Salvant J, Ravaud E, Eveno M, Men M, et al. A comparative study of Vincent Van Gogh's bedroom series. In: Spring M, editor. Studying old master paintings: technology and practice. In: The National Gallery Technical Bulletin 30th Anniversary Conference Post prints, Archetype: 2011. p. 237-43.

46. Hofenk de Graaff J, Karreman M, de Keijzer M, Roelofs W. A closer look: technical and art-historical studies on works by Van Gogh and Gauguin. In: Peres C, Hoyle M, van Tilborgh L, editors. Cahier Vincent 3: scientific investigation, vol. 3. Zwolle: Waanders Publishers; 1991. p. 75-85.

47. Vitorino T, Otero V, Carlyle L, Melo M, Parola A, Picollo M. Nineteenth-century cochineal lake pigments from Winsor and Newton: Insight into their methodology through reconstructions. In: Bridgland J, editor. ICOM-CC 18th triennial conference preprints, Copenhagen, 4-8 September 2017, international council of museums (Paris); 2017, p. art. 0107.

48. Kirby J, van Bommel M, Verhecken A. Natural colorants for dying and lake pigments: practical recipes and their historical sources. London: Archetype; 2014

49. Kühn H, Curran M. Chrome yellow and other pigments: a chrome yellow. In: Feller RL, editor. Artists' pigments, vol. 1. Cambridge: Cambridge University Press; 1986. p. 187-204.

50. Monico L, Van der Snickt G, Janssens K, De Nolf W, Miliani C, Verbeeck $J$, et al. Degradation process of lead chromate in paintings by Vincent van Gogh studied by means of synchrotron x-ray spectromicroscopy and related methods. 1. artificially aged model samples. Anal Chem. 2011;83:1214-23.

51. Monico L, Janssens K, Miliani C, Van der Snickt G, Brunetti BG, Guidi MC, et al. Degradation process of lead chromate in paintings by Vincent van Gogh studied by means of spectromicroscopic methods. 4. Artificial aging of model samples of co-precipitates of lead chromate and lead sulfate. Anal Chem. 2013;85:860-7.

52. Otero V, Pinto JV, Carlyle L, Vilarigues M, Cotte M, Melo MJ. Nineteenth century chrome yellow and chrome deep from Winsor and Newton TM. Stud Conserv. 2017;62:123-49.

53. MacLean J. Loodwitfabrieken in de negentiende eeuw. In: Rotterdams jaarboekje 1979; 1979. p. 233-52.

54. Ouweneel L. De Schoonhovensche loodwit-fabriek, wed. Hondorff Block \& Braet. Magazine "Het Leven in Schoonhoven" 2011:233-5.
55. Callen A. The art of impressionism: painting technique and the making of modernity. New Haven: Yale University Press; 2000.

56. Brill TB. Light: its interaction with art and antiquities. New York: Plenum Press; 1980.

57. Schaefer I, von Saint-George C, Lewerentz K. Painting light: the hidden techniques of the impressionists. Lausanne: Skira; 2008.

58. Gueli AM, Bonfiglio G, Pasquale S, Troja SO. Effect of particle size on pigments colour. Color Res. Appl. 2017;42:236-43. https://doi.org/10.1002/ col.22062.

59. Bomford D, Kirby J, Leighton J, Roy A. Art in the making: impressionism. London: National Gallery London; 1990.

60. Mayer R. The artist's handbook of materials and techniques. 5th ed. London and Boston: Faber and Faber; 1991.

61. Technical data available from Kremer pigmente. http://www.kremer-pigmente.com/media/pdf/45710e.pdf (Cobalt blue medium); http://www. kremer-pigmente.com/media/pdf/58700e.pdf (Blanc Fixe). Accessed 27 Feb 2018

62. Salvant J. Caractérisation des propriétés physico-chimiques des matériaux de peinture employés par Van Gogh: les peintures blanches. PhDthesis. C2RMF/UPMC; 2012

63. Völz H. Industrial color testing, fundamentals and techniques. 2nd ed. Weinheim: Wiley-VCH; 2001

64. Grum FC, Becherer R, Bartleson CJ. Optical radiation measurements, color measurement, vol. 2. Cambridge: Academic Press; 1980.

65. Kubelka P. New contributions to the optics of intensely light-scattering materials, part 1. J Opt Soc Am. 1948;38:448-57.

66. Duncan D. The colour of pigment mixtures. Proc Phys Soc. 1940;52:390-401.

67. Zhao Y, Berns RS. Predicting the spectral reflectance factor of translucent paints using Kubelka-Munk turbid media theory: review and evaluation. Color Res Appl. 2009;34:417-31.

68. Takei N, Yoshida T. Scattering and absorption coefficient of pigments. J Jpn Soc Colour Mater (Shikizai Kyokaishi). 1983;56:356-63.

69. Levinson R, Berdahl P, Akbari H. Solar spectral optical properties of pigments Part I: model for deriving scattering and absorption coefficients from transmittance and reflectance measurements. Sol Energy Mater Sol Cells. 2005;89:319-49.

70. Latour G, Elias M, Frigerio J-M. Determination of the absorption and scattering coefficients of pigments: application to the identification of the components of pigment mixtures. Appl Spectrosc. 2009;63:604-10.

\section{Submit your manuscript to a SpringerOpen ${ }^{\circ}$ journal and benefit from:}

- Convenient online submission

- Rigorous peer review

- Open access: articles freely available online

- High visibility within the field

- Retaining the copyright to your article

Submit your next manuscript at $\boldsymbol{\nabla}$ springeropen.com 